\title{
Vaccine-induced protection against 3 systemic mycoses endemic to North America requires Th17 cells in mice
}

\author{
Marcel Wüthrich, ${ }^{1}$ Benjamin Gern, ${ }^{1}$ Chiung Yu Hung, ${ }^{2}$ Karen Ersland, ${ }^{1}$ Nicole Rocco, ${ }^{1}$ \\ John Pick-Jacobs, ${ }^{1}$ Kevin Galles, ${ }^{1}$ Hanna Filutowicz, ${ }^{1}$ Thomas Warner, ${ }^{3}$ \\ Michael Evans, ${ }^{4}$ Garry Cole, ${ }^{2}$ and Bruce Klein ${ }^{1,5,6}$
}

\begin{abstract}
'Department of Pediatrics, University of Wisconsin School of Medicine and Public Health, Madison, Wisconsin, USA. 2Department of Biology and South Texas Center for Emerging Infectious Diseases, University of Texas at San Antonio, San Antonio, Texas, USA. ${ }^{3}$ Department of Pathology and Laboratory Medicine, ${ }^{4}$ Biostatistics and Medical Informatics, ${ }^{5}$ Department of Internal Medicine, and ${ }^{6}$ Department of Medical Microbiology and Immunology, University of Wisconsin School of Medicine and Public Health, Madison, Wisconsin, USA
\end{abstract}

\begin{abstract}
Worldwide rates of systemic fungal infections, including three of the major pathogens responsible for such infections in North America (Coccidioides posadasii, Histoplasma capsulatum, and Blastomyces dermatitidis), have soared recently, spurring interest in developing vaccines. The development of Th1 cells is believed to be crucial for protective immunity against pathogenic fungi, whereas the role of Th17 cells is vigorously debated. In models of primary fungal infection, some studies have shown that Th17 cells mediate resistance, while others have shown that they promote disease pathology. Here, we have shown that Th1 immunity is dispensable and that fungus-specific Th17 cells are sufficient for vaccine-induced protection against lethal pulmonary infection with $B$. dermatitidis in mice. Further, vaccine-induced Th17 cells were necessary and sufficient to protect against the three major systemic mycoses in North America. Mechanistically, Th17 cells engendered protection by recruiting and activating neutrophils and macrophages to the alveolar space, while the induction of Th17 cells and acquisition of vaccine immunity unexpectedly required the adapter molecule Myd88 but not the fungal pathogen recognition receptor Dectin-1. These data suggest that human vaccines against systemic fungal infections should be designed to induce Th17 cells if they are to be effective.
\end{abstract}

\section{Introduction}

Vaccines that prevent infectious disease have been hailed as the greatest achievement in public health over the last century (1). The soaring rates of systemic fungal infections worldwide have spurred interest in developing vaccines (2-8). Experimental vaccines against fungi are under study, but none are in clinical trials or commercially available (6). We and others have engineered vaccines that protect against experimental infection with the primary pathogenic fungi Coccidioides posadasii (9), Histoplasma capsulatum (10), and Blastomyces dermatitidis (11), which cause the major systemic mycoses of North America and account for one million new infections annually (12). A dominant Th 1 cell response mediated by IL-12 is thought to be essential for protective immunity against these $(9-11,13,14)$ and other pathogenic fungi $(2,15)$. Ablation of IL-12 or IFN- $\gamma$ worsens the course of fungal infections $(13,14,16,17)$. IFN- $\gamma$, the signature cytokine of antigen-specific (Ag-specific) Th1 cells, activates phagocytes to kill fungi at sites of infection (14).

IL-17 and Th17 cells participate in the host response to fungi during primary infections in nonimmune hosts, but the literature is at odds as to whether Th17 cells play a helpful or harmful role. IL-17 receptor A knockout (Il17 $\left.\mathrm{ra}^{-/-}\right)$mice are susceptible to systemic Candida albicans infection due to reduced infiltration of neutrophils into infected organs (18). Likewise, Th17 cell-deficient

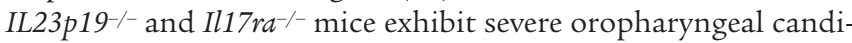
diasis, while Th1 cell-deficient Il12p35 $5^{-/-}$mice show a low fungal

Conflict of interest: The authors have declared that no conflict of interest exists. Citation for this article: J Clin Invest. 2011;121(2):554-568. doi:10.1172/JCI43984. burden and no overt disease (19). IL-17 also promotes host defense against primary pulmonary infection with Pneumocystis carinii (20), H. capsulatum (21), and Aspergillus fumigatus (22).

In sharp contrast to the studies cited above, the pathogenic and regulatory role of IL-17 in limiting protective Th1 responses has been highlighted in models involving intragastric delivery of C. albicans and intranasal administration of A. fumigatus (23). At these mucosal sites, Th17 cells exacerbate inflammation and fungal infection and produce severe tissue pathology. These differences imply that the influence of Th17 cells on the course of fungal disease may be affected by the disease model, timing of Th17 cell recruitment, tissue inoculum, and balance of pathogen versus Th17 cellular response at a given time during the course of infection. Although Th17 cells damage tissue in response to fungi during the course of primary infections or autoimmune conditions, it is plausible that they could be engaged for vaccine immunity where the response is rapid and early after fungal exposure and not delayed by the need for Th17 differentiation.

The differentiation of Th17 cells in response to fungi has been a subject of intense study. Dectin-1 is a pattern recognition receptor for fungi that is part of a novel innate signaling pathway involving Syk kinase $(24,25)$ and the adaptor Card9 (26-28), which in turn are critical for inducing Th17 responses to fungal infection. Dectin $1^{-/}$mice show impaired resistance to C. albicans, $P$. carinii, and A. fumigatus infection $(22,29,30)$. Without Dectin-1, lung immunity against $A$. fumigatus yields less IL-17, reduced proinflammatory cytokine and chemokine production by alveolar macrophages, and fewer neutrophils, which also display defective antifungal defense mechanisms (22). Collectively, this work has indicated that Dectin/ 
Syk kinase/Card9 signaling are instrumental in the differentiation of Th17 cells and their downstream functions in response to infection with opportunistic fungi.

We asked the following here: (a) whether Th17 cells are or can be engaged by vaccination to confer resistance to fungi, and if so, (b) how Th17 cells are induced by vaccine to differentiate from naive $\mathrm{T}$ cells into antifungal Th17 effectors. We report that vaccineinduced Th17 cells protect against lethal experimental infection with agents of the systemic mycoses of North America, B. dermatitidis, C. posodasii, and H. capsulatum. Th17 cells confer resistance in the absence of Th1 immunity and alone are sufficient for protection. Th17 cells recruit and activate neutrophils and macrophages to the alveolar space. Unexpectedly, vaccine induction of Th17 cells requires Myd88, not Dectin-1.

\section{Results}

Naive T cells differentiate into Th17 cells upon vaccination. The role of Th17 cells has been studied mainly during primary fungal infection (18, $20,23,31)$. Here, we explored whether Th17 cells are induced during the afferent phase of vaccination against $B$. dermatitidis. We have reported that Th1 cells are induced (11) and here compared that response to Th17 cell development. After vaccine, CD4 T cells from the draining nodes produced IL-17 and IFN- $\gamma$ transcript and protein in response to $\mathrm{Ag}$ (Figure 1, A and B). To confirm the phenotype of primed CD4 $\mathrm{T}$ cells that traffic to the vaccine site, we stained the cells for intracellular cytokine. Endogenous, polyclonal cells and B. dermatitidis-specific Tg CD4 ${ }^{+} \mathrm{T}$ cells (Wüthrich et al., unpublished observations) adoptively transferred before vaccination made IL-17 and IFN- $\gamma$ (Figure 1C). $25 \%$ of these IL-17-producing $\mathrm{CD}^{+}{ }^{+}$cells in the skin produced IFN- $\gamma$ (Table 1$)$. The proportion of Th17 cells among TCR Tg cells was greater than in the endogenous pool of $\mathrm{CD}^{+} \mathrm{T}$ cells, implying that Th17 cells in the latter pool are Ag-specific.

Th17 effector cells migrate to the lung and make IL-17 and IL-22 during recall. To see whether primed Th17 cells migrate to the lung of vaccinated mice after a pulmonary challenge, we assayed transcript and the number of cytokine-producing lung $\mathrm{T}$ cells. Transcripts for type 17 cytokines IL-17A and IL-17F, and IL-22 and type 1 cytokine IFN- $\gamma$ were elevated in vaccinated mice versus unvaccinated controls during the first 3 days after infection (Figure 1D). To see whether the difference in cytokine production stems from primed CD4 T cells, we stained lung T cells for intracellular cytokine. The percentage and number of IL-17- and IFN- $\gamma$-producing $T$ cells rose sharply in vaccinated versus unvaccinated mice by day 2 after infection and remained significantly higher until day 6 (Figure 1E). Cytokine production was chiefly confined to $\mathrm{CD} 44^{+} \mathrm{CD} 62 \mathrm{~L}^{\text {lo }} \mathrm{CD} 4^{+} \mathrm{T}$ cells (data not shown). From $4 \%$ to $8 \%$ of the IL- 17 -producing $\mathrm{CD}^{+}$cells also produced IFN- $\gamma$ upon recall (Table 1 ). The number of $\mathrm{IL}-17^{+}$endogenous and B. dermatitidis-specific TCR Tg CD4 ${ }^{+} \mathrm{T}$ cells recruited to the lung rose similarly during the first 4 days after infection and increased in a vaccine-dose-dependent manner (Supplemental Figure 1; supplemental material available online with this article; doi:10.1172/ JCI43984DS1). The number of cytokine-producing Th17 and Th1 cells correlated with lung CFU in vaccinated and unvaccinated mice. Vaccinated mice reduced lung CFU by day 2 after infection, and by day 6 most had cleared the yeast from their lungs. In unvaccinated mice, lung CFU stayed at the input level for the first 4 days and then grew until the mice were moribund at day 15 (Figure 1F). Thus, the onset of Th17 and Th1 cytokine-producing T cells in the lung coincided with the reduction in lung CFU.
IL-17 mediates vaccine immunity during the efferent phase. Since Th17 cells are induced during the afferent phase after vaccination and they migrate to the lung and express type 17 cytokines during the efferent (recall) phase, we tested whether IL-17 contributes functionally to vaccine resistance. We used 3 approaches. First, we neutralized IL-17 in vaccinated C57BL/6 mice after pulmonary challenge. IL-17 neutralization increased lung CFU by more than 3 logs compared with rat IgG-treated control mice (Figure 2A). Neutralization of IFN- $\gamma$ increased lung CFU 61-fold versus rat IgG control, and neutralization of IL-17 and IFN- $\gamma$ together did not have an additive effect.

In a second approach, also designed to block IL-17 action during the vaccine efferent phase, we treated mice with adenovirus that overexpresses soluble IL-17R:Fc fusion protein (32-34), which binds IL-17 and blocks its receptor binding. IL-17 neutralization with IL-17R:Fc in vaccinated mice after pulmonary challenge increased lung CFU by 1,630-fold versus AdLuc-treated control mice (Figure 2B). Neutralization of IL-17 in unvaccinated mice increased lung CFU by only 4- to 5-fold versus AdLuc controls, indicating IL-17 exerted its effect during vaccine immunity. We extended these findings to a second inbred strain of mice, BALB/c. Neutralization of IL-17 by $\mathrm{mAb}$ and soluble IL-17R:Fc yielded similar results in vaccinated BALB/c mice (Supplemental Figure 2, A and B).

In a third approach, to further address the roles of IL-17 and IL-17A/IL-17R signaling, we investigated resistance in vaccinated Il17 $\mathrm{ra}^{-/-}$mice. Mouse Th17 cells produce only IL-17A and IL-17F $(35,36)$, which both signal through IL-17RA. Thus, even if $I l 17 \mathrm{ra}^{-/-}$ mice develop vaccine-induced Th17 and Th1 cells, IL-17 could not signal via its receptor to mediate its effector functions. We first analyzed the Th17 and Th1 phenotypes in $I l 17 \mathrm{ra}^{-/-}$mice. At 4 days after infection, the numbers of primed Th17 and Th1 cells recalled to the lung were similar in vaccinated $\mathrm{Il}_{17 \mathrm{ra}^{-/}}$and wild-type mice (Figure 2C). Lung transcript of IFN- $\gamma$ (and IL-4) was similar between the groups (Figure 2C). Thus, Th17 and Th1 cell development and migration to the lung were not impaired in the absence of IL-17R signaling. Intact IL-17 signaling apparently was not required to prime and recruit antifungal Th1 cells into the lung, in contrast to infections with Mycobacterium tuberculosis (37) and Francisella tularensis (38). Despite unimpaired Th1 function in vaccinated $\mathrm{Il}_{17 \mathrm{ra}^{-/}}$mice, they had lung CFUs more than 400-fold higher than wild-type mice. In contrast, the lung CFUs were similar in unvaccinated $I l 17 \mathrm{ra}^{-/}$mice and wild-type controls (Figure 2D). Thus, Th17 cells mediate vaccine immunity to fungi independent of Th1 cells, and innate IL-17-producing cells appear to play a negligible role in explaining this resistance.

$I L-17 A$ is obligate for vaccine immunity. Although IFN- $\gamma$ and TNF- $\alpha$ regulate the expression of vaccine immunity to fungi in wild-type mice, both cytokines are dispensable upon vaccination of Ifng $^{-/}$and Tnfa- mice (14). To see whether IL-17A is obligate or dispensable in vaccine immunity, we immunized $I l 17 a^{-/-}$mice and tested their resistance to lethal pulmonary infection (Figure 2E). Vaccinated $I l 17 a^{-/}$mice had more than 2 log more lung CFUs than wild-type controls. Similarly to $I l 17 \mathrm{ra}^{-/-}$mice, $I l 17 \mathrm{a}^{-/-}$mice were only slightly more susceptible to primary infection than wild-type mice.

The early production of IL-17 upon bacterial challenge in the lung is needed to recruit primed Th1 cells that reduce the bacterial burden (37). We therefore tested the type 1 cytokine response in vaccinated $I l 17 a^{-/-}$mice 3 to 4 days after infection, when the number of cytokine-producing $\mathrm{T}$ cells peaks in vaccinated mice. The expression of lung IFN- $\gamma$ transcript and the number of IFN- $\gamma-$ 

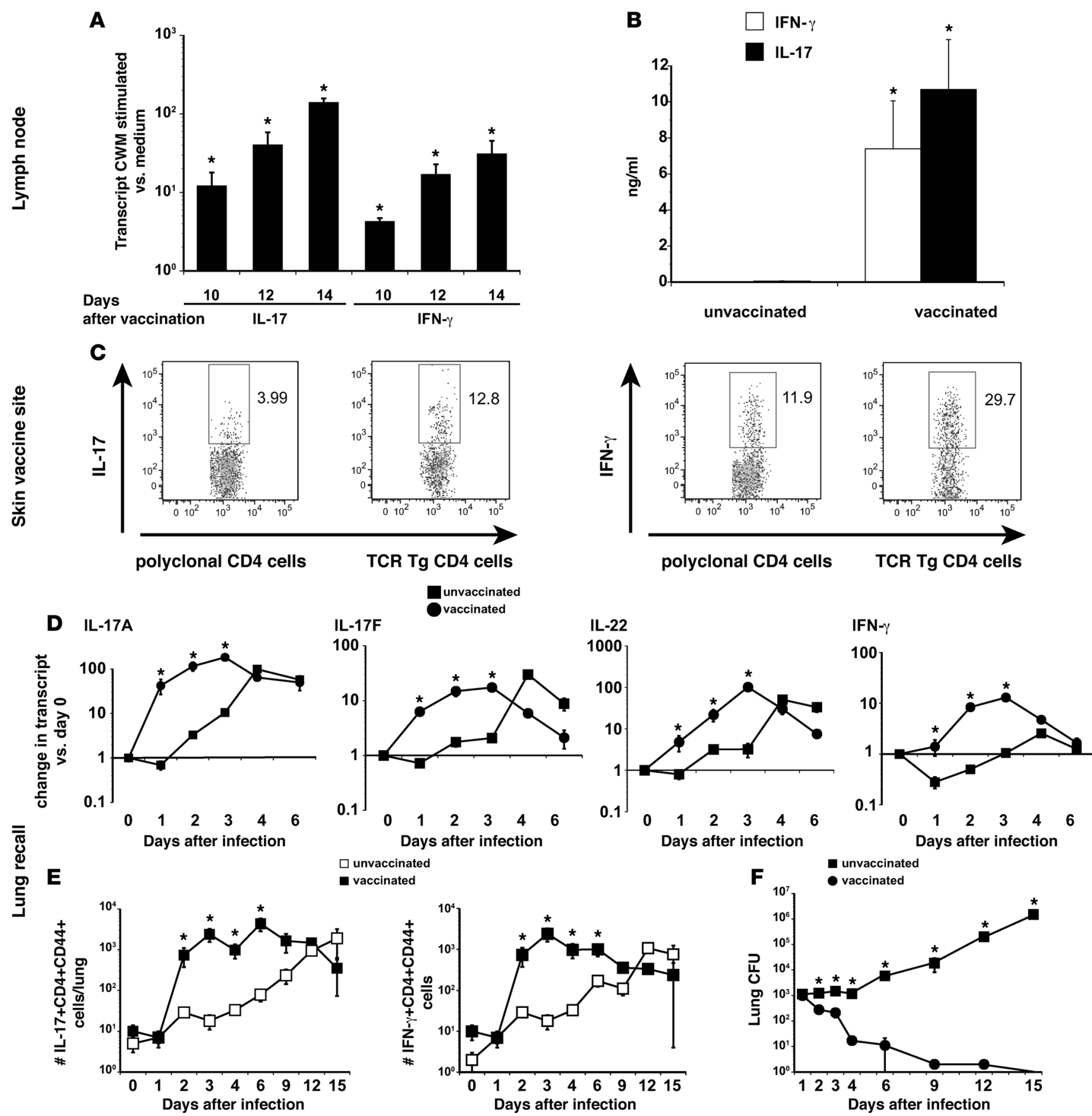

Figure 1

Naive CD4 T cells differentiate into Th17 cells during the afferent phase of vaccination and are recalled to the lung during the efferent phase. (A) Ag-specific Th17 cells accumulate in the skin-draining lymph nodes during vaccine induction. Purified CD4 T cells from the skin-draining lymph nodes of vaccinated mice were cocultured with CW/M Ag for 2 days and cytokine transcripts analyzed by RT-PCR. Mean \pm SEM $(n=3)$; representative of 3 experiments. (B) Primed Th17 cells produce IL-17 in response to in vitro Ag stimulation. 3 weeks after the boost, purified CD4 T cells from the draining nodes were stimulated with CW/M Ag for 3 days and the supernatants analyzed. Mean \pm SEM $(n=4)$; representative of 3 experiments. (C) Th17 cells infiltrate the vaccine site. Lymphocytes were isolated from the vaccine site. To verify cytokine response by Agspecific T cells, $B$. dermatitidis-specific $1807 \mathrm{Tg}$ cells were transferred into recipients before vaccination. T cells from the site were stimulated with $\alpha$-CD3 and $\alpha$-CD28 mAb for 4 hours and analyzed for intracellular cytokine. Dot plots show percentage of cytokine-producing polyclonal or Tg CD4 cells. ( $D$ and $\mathbf{E}$ ) Th17 effector cells migrate to the lung during the recall and vaccine efferent phase. Vaccinated mice were challenged with $B$. dermatitidis i.t. and the expression of lung cytokine transcript was measured by RT-PCR. For the kinetics of IL-17- and IFN- $\gamma-$ producing CD4 T cells, the number of cytokine-producing cells was calculated by multiplying the number of total lung cells by the percentage of cytokineproducing CD4 T cells. Mean \pm SEM $(n=4)$; representative of 3 experiments. (F) Lung CFUs coincide with number of cytokine-producing CD4 T cells. Mean \pm SEM $(n=8-10)$; representative of 2 experiments. ${ }^{*} P<0.05$ versus unvaccinated mice. 


\section{Table 1}

Dual producing CD4 T cells: IL-17-positive cells that produce IFN- $\gamma$ and vice versa in the skin and in the lung upon recall

$\begin{array}{lccc} & & \text { IFN- } \gamma \text {-producing } & \text { IL-17-producing } \\ \text { CD4 T cells } & \text { Source } & \text { IL-17-positive cells (\%) } & \text { IFN- } \boldsymbol{\gamma} \text {-positive cells (\%) } \\ 1807 & \text { Skin } & 25.1 \pm 3.9 & 10.6 \pm 1.7 \\ \text { Endogenous, polyclonal CD4 } & \text { Skin } & 24.8 \pm 7.2 & 10.2 \pm 3.1 \\ 1807 & \text { Lung } & 7.7 \pm 2.1 & 14.4 \pm 3.1 \\ \text { Endogenous, polyclonal CD4 } & \text { Lung } & 3.9 \pm 0.7 & 10.6 \pm 1.3\end{array}$

Lymphocytes were isolated from the vaccine site and the lungs of vaccinated and challenged wild-type mice that received $10^{5}$ naive 1807 cells prior to vaccination. T cells were stimulated with $\alpha-C D 3$ and $\alpha$-CD28 mAb for 4 hours and analyzed for intracellular cytokine. The frequency of IL-17+ and IFN- $\gamma^{+}$ double-producing cells was determined as follows: 1807 and polyclonal, endogenous CD4 cells that expressed IL-17 were analyzed for the percentage of IFN- $\gamma$-producing cells and vice versa. Data represent the mean \pm SEM of 4 mice/group; representative of 3 experiments.

The recruitment of polymorphonuclear cells (PMNs) into the lung was similarly minimal in vaccinated Ill2rb2-/-, Tbet ${ }^{-1}$, and wild-type mice. In contrast, unvaccinated mice of all 3 strains showed massive infiltration of PMNs and macrophages. Thus, in the absence of Th1 immunity, vaccinated Il12rb2 $2^{-/}$, Tbet ${ }^{-/}$, and Tbet $^{-1-}$ Stat $4^{-/-}$mice were resistant and showed no signs of increased inflammation and tissue destruction.

Ag-specific Th17 cells are sufficient to mediate vaccine immunity. Since Th17 immunity was unaltered or slightly elevated in Th1-deficient Il12rb2and Tbet $^{-1}$ mice, we hypothesized that Ag-specific, Th17 cells are suf-

producing CD4 T cells was similar or increased in vaccinated $I l 17 \mathrm{a}^{-/-}$ mice compared with wild-type controls (Figure 2C and data not shown). Lung IFN- $\gamma$ and IL-4 transcripts were higher in vaccinated $I l 17 \mathrm{a}^{-/-}$mice versus vaccinated wild-type controls, indicating that Th1 and T2 cytokines were not diminished in the absence of IL-17A. Hence, the loss of IL-17A did not impair the induction or recruitment of Th1 cells, but was obligate for vaccine immunity.

Th1 cells are dispensable for vaccine immunity. We analyzed vaccine immunity against fungi in the absence of Th1 cells. We vaccinated mice that lack components of the IL-12/Stat4 pathway (39) or IFN- $\gamma$ / T-bet (40) pathway needed to develop Th1 immunity and studied their T helper and resistance phenotypes. We used Il12p35-/- and Il12rb2 $2^{-/-}$mice to target the IL-12 pathway; Tbet ${ }^{--}$mice for that pathway; and Tbet ${ }^{-1}$ Stat $4^{-/-}$mice to eliminate both pathways. Vac-

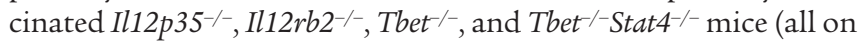
the C57BL/ 6 background) (Figure 3, A-D) and Ifng ${ }^{-/}$mice (on the BALB/c background) (Supplemental Figure 2A) were as resistant as wild-type mice to pulmonary challenge. Thus, IL-12, T-bet, and IFN- $\gamma$ signaling are dispensable in vaccine resistance. In contrast, mice lacking the p40 subunit shared between the heterodimeric IL-12 and IL-23 cytokines did not acquire vaccine immunity (Figure 3A). Since IL-23 is required for maintenance of Th17 cells, this result implies that Th17 cells are required for vaccine immunity, whereas Th1 cells are dispensable.

To see how the loss of Th1 differentiation factors IL-12 and T-bet affected $\mathrm{T}$ helper development, we analyzed the phenotypes of vaccine-induced CD4 $\mathrm{T}$ cells during recall after pulmonary challenge. Vaccinated Il12rb2 $2^{-/-}$, Tbet ${ }^{-/}$, and Tbet ${ }^{-/}$Stat $4^{-/-}$mice had 4- to 50-fold less IFN- $\gamma$ lung transcript, 2- to 3-fold fewer IFN- $\gamma$-producing CD4 cells in the lungs, and 10 -fold or more fewer Ag-specific IFN- $\gamma$ protein in vitro versus wild-type controls (Supplemental Figure 3, A-D). In contrast, the expression of IL-17A (and IL-4) was not significantly altered in these mice, indicating that primed $\mathrm{T}$ cells were not skewed toward a Th17 or Th2 phenotype. Thus, Ill2rb2-/- and Tbet ${ }^{--}$mice acquired vaccine immunity despite impaired Th1 immunity, implying that vaccine-induced Th17 cells may confer protection.

In primary infection models of intragastric candidiasis and pulmonary aspergillosis, Th17 cells promote tissue inflammation and pathology and impair resistance (23). To see whether immunity in Il12rb2 $2^{-/-}$and Tbet ${ }^{--}$mice induces tissue injury and pathology, we analyzed lung histology in the vaccinated mice at 2 weeks after infection when unvaccinated mice were moribund (Figure 3E). ficient to mediate antifungal resistance. To test this, we used 2 approaches, each exploiting $B$. dermatitidis-specific TCR Tg cells. First, we generated in vitro polarized Tg cells, making substantial IL-17, and adoptively transferred these Th17 effector cells into nonirradiated or sublethally irradiated wild-type mice. Since adoptively transferred Th17 effectors can deviate into Th1 cells (41), we also crossed B. dermatitidis TCR Tg 1807 mice with $I l 12 r b 2^{-/-}$ and Tbet ${ }^{--}$mice to generate Il12rb2 $2^{-/-} \times 1807$ and Tbet $^{--} \times 1807$ mice that lack IL-12 or T-bet signaling to prevent deviation into Th1 effectors. The polarization in vitro of $1 l 12 \mathrm{rb2}^{-\gamma^{-}} \times 1807$ cells, Tbet ${ }^{-} \times 1807$ cells, and wild-type 1807 cells yielded approximately $20 \%$ IL-17- and less than $1 \%$ IFN- $\gamma$ - producing TCR Tg cells (Figure 4A and data not shown). One day after adoptive transfer into nonirradiated mice and 8 weeks after transfer into irradiated animals (to reconstitute the lymphoid organs), mice were challenged to assess resistance. Nonirradiated recipients of "wild-type" 1807 cells, Il12rb2 $2^{-/} \times 1807$ cells, or Tbet $^{-/} \times 1807$ cells had 5- to 10-fold less lung CFU than mice that received Th17-polarized OT2 (control) cells (Figure 4B). Polarized Th17 Tg cells remained committed to their lineage phenotype on recall to the lung (Supplemental Figure 4A). The relative number of IL-17-versus IFN- $\gamma$-producing 1807 cells in the lung was 8-, 21-, and 28-fold higher for wild-type 1807 cells, Il12rb2 $2^{-/} \times 1807$ cells, and Tbet ${ }^{--} \times 1807$ cells, respectively.

The lung CFU were more than 70 -fold lower in irradiated recipients of polarized wild-type 1807 cells or $I l 12 \mathrm{rb2}^{-/} \times 1807$ cells than in OT2 control mice (Figure 4C). The greater CFU reduction in irradiated recipients was likely due to more expansion of Tg cells in lymphopenic recipients. From intracellular cytokine staining of lung cells, transferred Tg cells remained polarized toward a Th17 phenotype (Supplemental Figure 4B); however, in vitro Ag stimulation of lymph node cells showed a less polarized Th17 phenotype (data not shown), as might be expected after expansion in lymphopenic mice (41).

Consequently, we pursued another approach. We generated Ag-specific Th17 cells in vivo by adoptive transfer of naive $I l 12 \mathrm{rb2}^{-/-} \times 1807$ cells or Tbet ${ }^{--} \times 1807$ cells into OT1 recipients before vaccination. OT1 mice have few endogenous CD4 T cells and fail to acquire vaccine immunity (Wüthrich et al., unpublished observations). We hypothesized that, without IL-12 and T-bet signaling, 1807 cells would differentiate chiefly into Th17 cells. OT1 recipients of Il12rb2 $2^{--} \times 1807$ cells, Tbet $^{--} \times 1807$ cells, or wild-type 1807 cells before vaccination had approximately 3 to $5 \log$ less lung CFU than OT1 recipients of control OT2 cells (Figure 4D). Vaccine-induced 
A

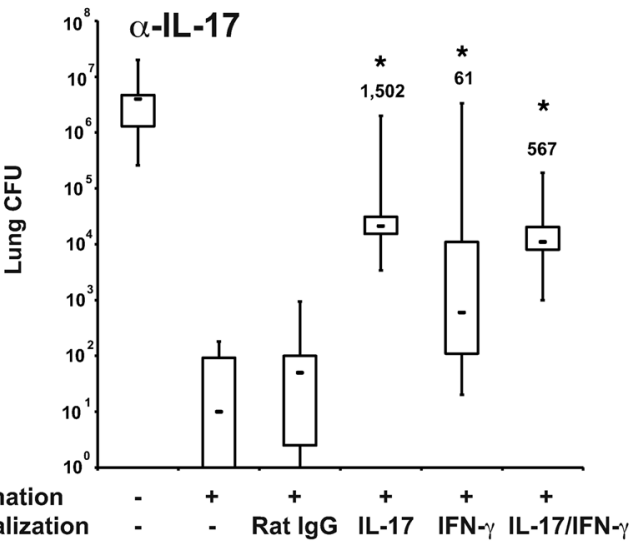

$\begin{array}{lllllll}\text { Vaccination } & - & + & + & + & + & + \\ \text { Neutralization } & - & - & + & + \\ \text { Rat IgG } & \text { IL-17 } & \text { IFN }-\gamma \text { IL-17/IFN }-\gamma\end{array}$
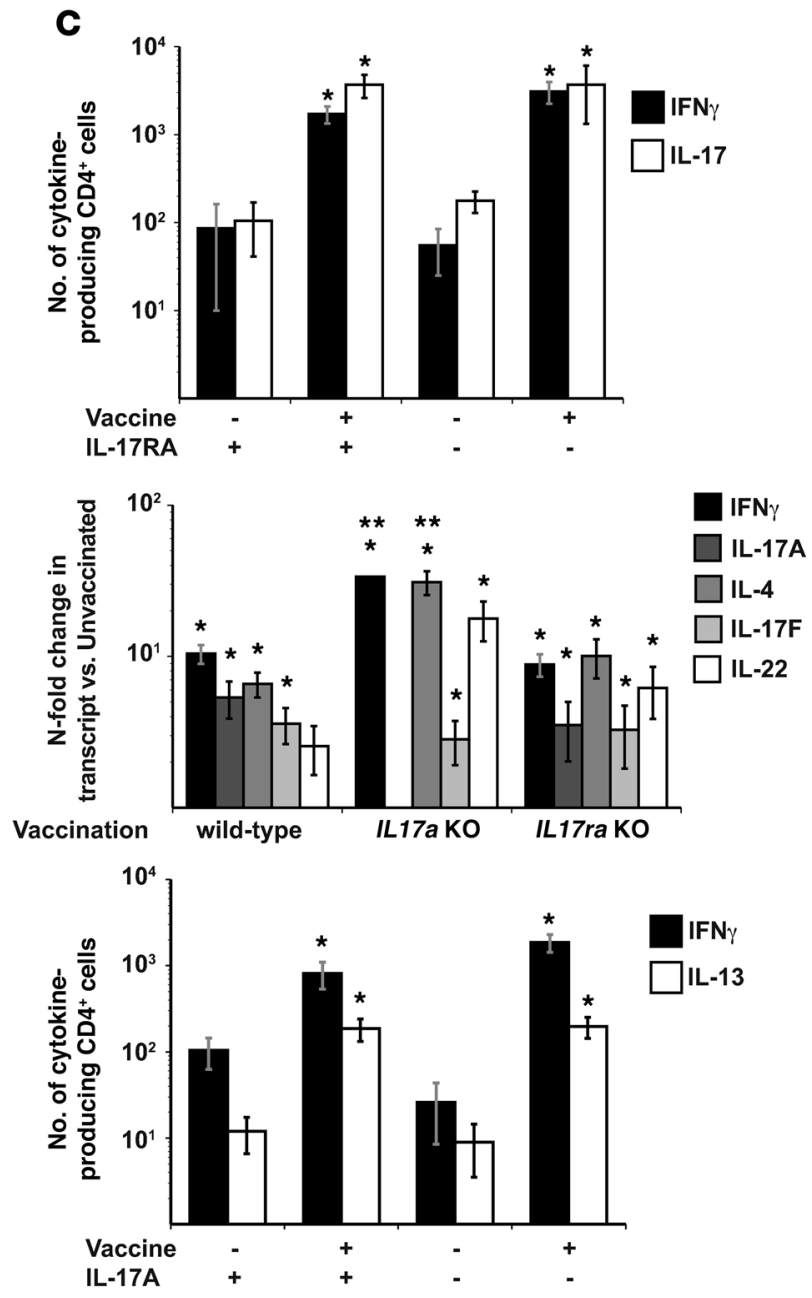

B
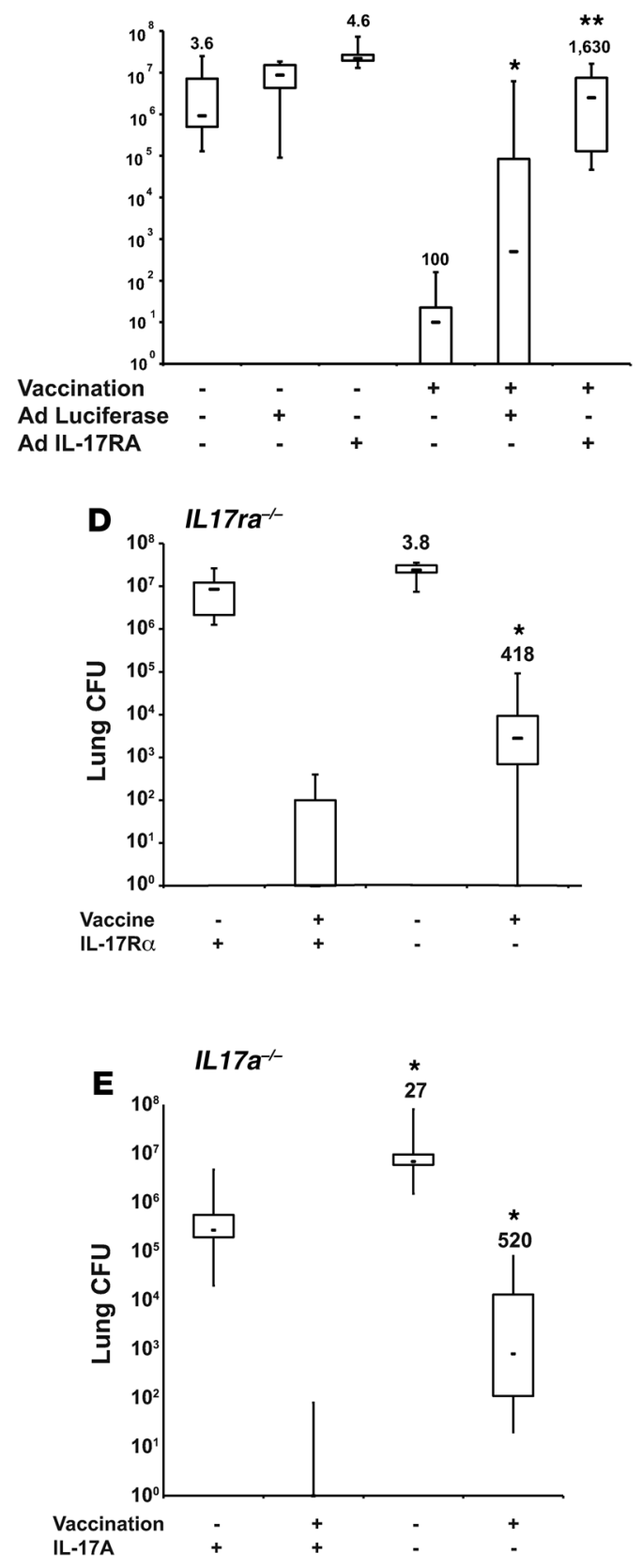

Figure 2

IL-17 mediates vaccine immunity against $B$. dermatitidis infection. (A) Antibody neutralization of IL-17 in vaccinated mice after infection. Lung CFU are the mean \pm SEM $(n=10-12)$. Numbers shown are the relative increase in lung CFU of mAb-treated versus rat IgG controls. ${ }^{*} P<0.001$ versus vaccinated mice treated with rat IgG. (B) Neutralization of IL-17 by soluble IL-17 receptor (IL-17R:FC). Values are the mean \pm SEM ( $n=10-18$ ); representative of 2 experiments. Numbers shown are the fold increase in lung CFU versus AdLuc-treated controls. ${ }^{*} P<0.001$ versus vaccinated mice not treated with adenovirus; ${ }^{* \star} P<0.001$ versus vaccinated mice treated with AdLuc. (C) Lung transcripts and number of primed Th1 and Th17 cells recruited to the lung upon fungal challenge in $/ / 17 \mathrm{a}^{-/-}$and $/ 117 \mathrm{ra}^{-/-}$mice. RNA from lung (middle panel) and the absolute number of IL-17-, IFN- $\gamma-$, or IL-13-producing CD4 ${ }^{+}$CD $44^{+}$T cells were quantified by real-time PCR and FACS. Data are mean \pm SEM $(n=4-6)$; representative of 2 experiments. ${ }^{*} P<0.05$ versus unvaccinated controls; ${ }^{\star \star} P<0.05$ versus vaccinated wild-type and $/ / 17 \mathrm{ra}^{-/-}$mice (D) IL-17RA is required for vaccine immunity. Mean \pm SEM $(n=8-12)$; representative of 2 experiments. ${ }^{*} P<0.001$ versus vaccinated wild-type. (E) IL-17A is required for vaccine immunity. Lung CFU are the mean $\pm \operatorname{SEM}(n=10-12)$; representative of 2 experiments. Numbers shown in $\mathbf{D}$ and $E$ are the fold increase in CFU versus corresponding wild-type controls. ${ }^{*} P<0.001$ versus wild-type mice. 

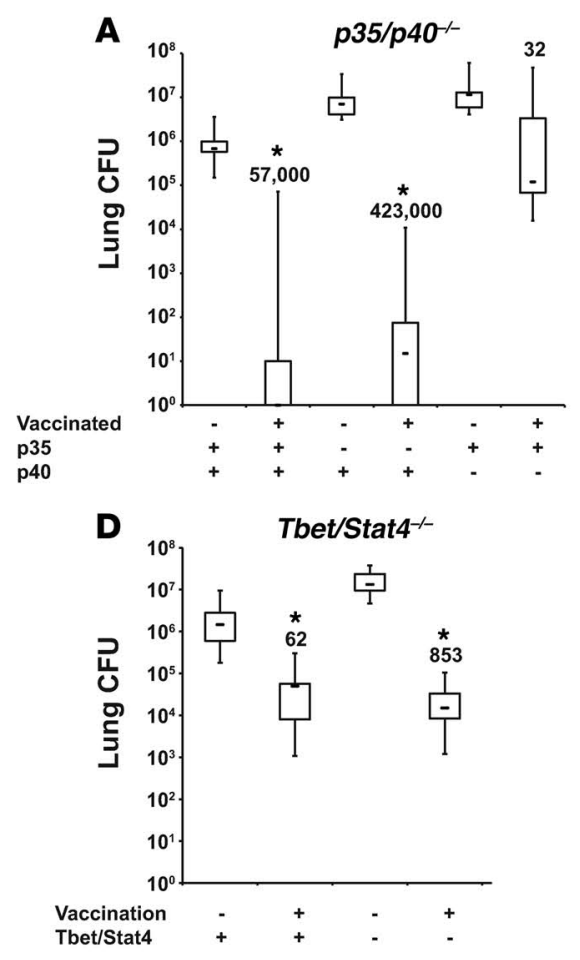
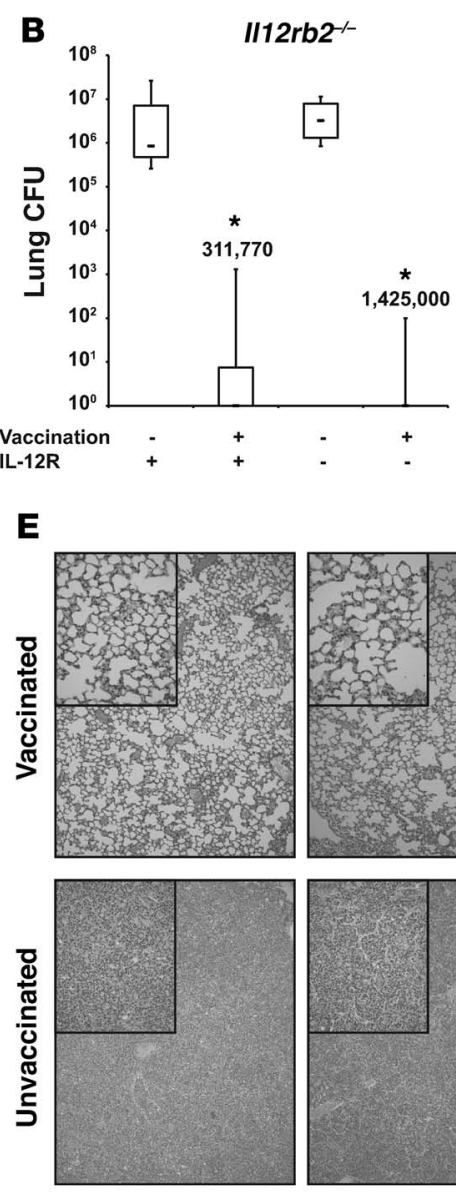

WT
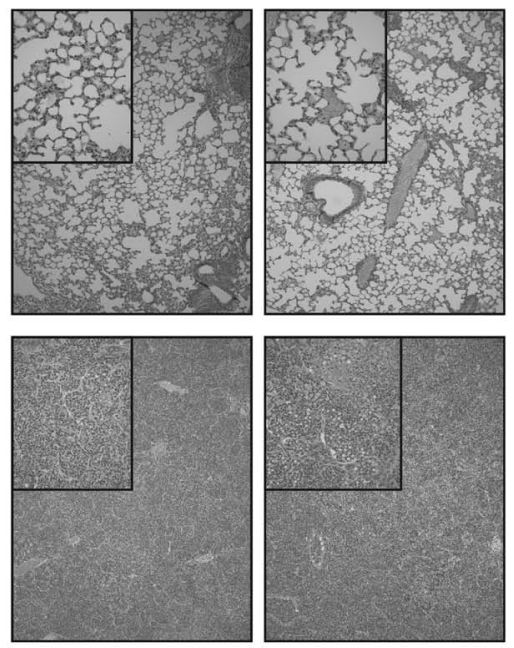

1112 rb2 $^{-1-}$

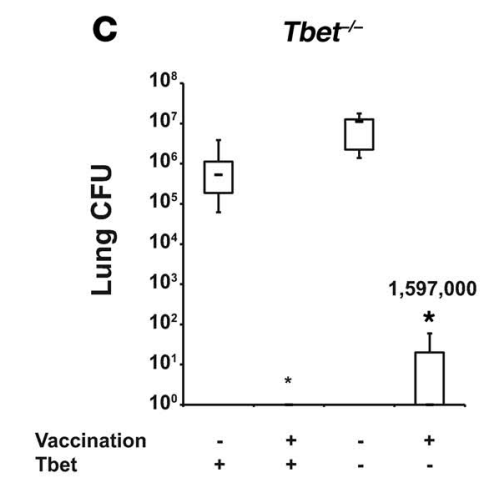

Figure 3

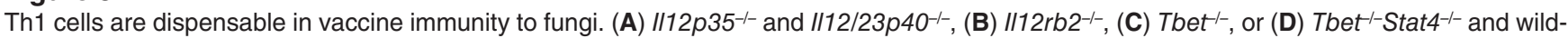
type mice were vaccinated and challenged with $B$. dermatitidis as in Methods and the lung CFU analyzed. CFU values are the mean \pm SEM of 10-12 mice/group; representative of 2 experiments per group. The numbers shown are fold reduction in lung CFU versus unvaccinated controls. ${ }^{*} P<0.001$ versus unvaccinated controls and vaccinated $p 40^{-1-}$ mice. (E) Vaccine-induced Th17 cells do not mediate lung pathology. Histology (16 days after infection) of lungs from wild-type and Th1-deficient vaccinated mice showed normal lung alveolar parenchyma with few foci of perivascular lymphocytes, but no PMN infiltrates. In contrast, lungs from unvaccinated mice showed massive infiltration with PMNs and macrophages and many yeast. Original magnification, $\times 100 ; \times 400$ (insets).

Il12rb2 $2^{-/} \times 1807$ cells and Tbet ${ }^{-/} \times 1807$ cells recruited to the lung after challenge had a polarized Th17 phenotype, whereas wild-type 1807 cells were divided into Th17 and Th1 cells (Figure 4E). Thus, Il12rb2 $2^{-/-} \times 1807$ cells and Tbet $^{-/} \times 1807$ cells differentiated chiefly into Th17 cells in vivo and were sufficient to confer protection.

Th17 cells mediate vaccine resistance to $C$. posadasii and $H$. capsulatum. We used 2 other models in which s.c. injection of vaccine protects against experimental histoplasmosis (10) and coccidioidomycosis (9) to see whether our findings apply to other dimorphic fungi. We first tested to determine whether Th17 cells are induced by C. posadasii vaccination using live spores from a genetically engineered, attenuated mutant strain ( $\Delta \mathrm{T}$ vaccine) lacking chitinase 2 and 3 and $\mathrm{D}$-arabinotol-2-dehydrogenase, and recalled to the lung on pulmonary challenge. IL- 17 transcript and $\mathrm{CD} 4^{+} \mathrm{CD} 44^{+} \mathrm{T}$ cells that expressed IL-17 protein appeared at day 5 and peaked 7-11 days after infection of vaccinated mice, whereas unvaccinated mice failed to recruit Th17 cells to the lung (Figure 5, A and B, and Supplemental Figure 5A). CD4 T cells from the skin-draining lymph nodes of vaccinated mice also produced IL-17 when stimulated with T27K Ag (ref. 42 and Figure 5C). After pulmonary challenge with C. posadasii, the kinetic of Th17 cell recruitment to the lung correlated with the reduction of lung CFU (Supplemental Figure 5B)

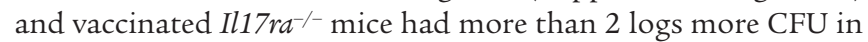
the lungs and spleen versus vaccinated controls (Figure 5D).

Mice vaccinated with $H$. capsulatum also recruited more IL-17producing (and IFN- $\gamma$-producing) CD4 T cells to the lungs after infection than did unvaccinated controls (Figure 5E). Balb/C mice showed similar percentages of Th17 and Th1 cells in their lungs, whereas C57BL/6 mice had more Th1 cells. To see whether Th17 cells confer vaccine immunity to $H$. capsulatum, we vaccinated and

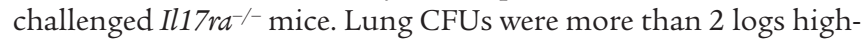

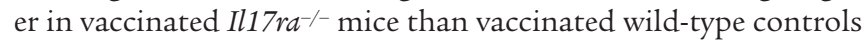
(Figure 5F). The T helper phenotypes of IL-17RA and wild-type mice during the recall were comparable (Supplemental Figure 5). Thus, Th17 cells also mediate vaccine immunity to both C. posadasii and $H$. capsulatum infection. 
A

Th17 polarization

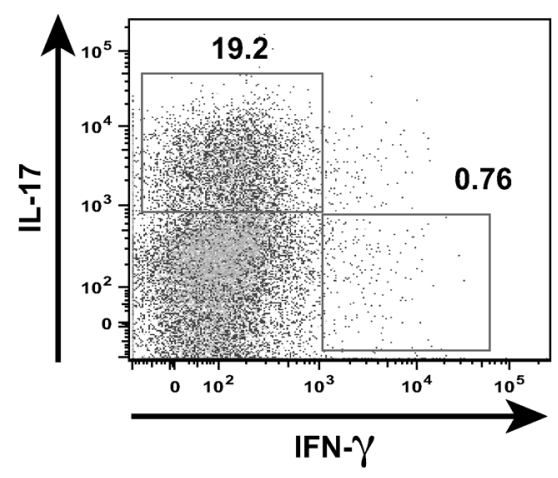

C

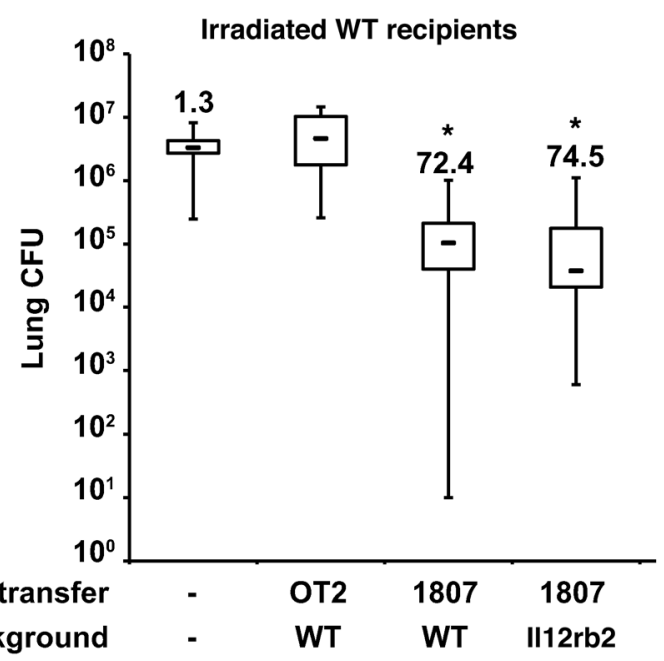

$\mathbf{E}$

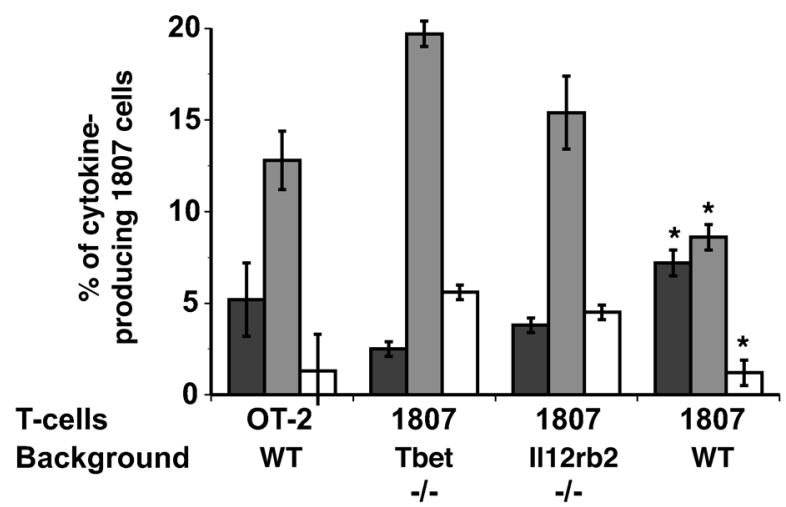

B

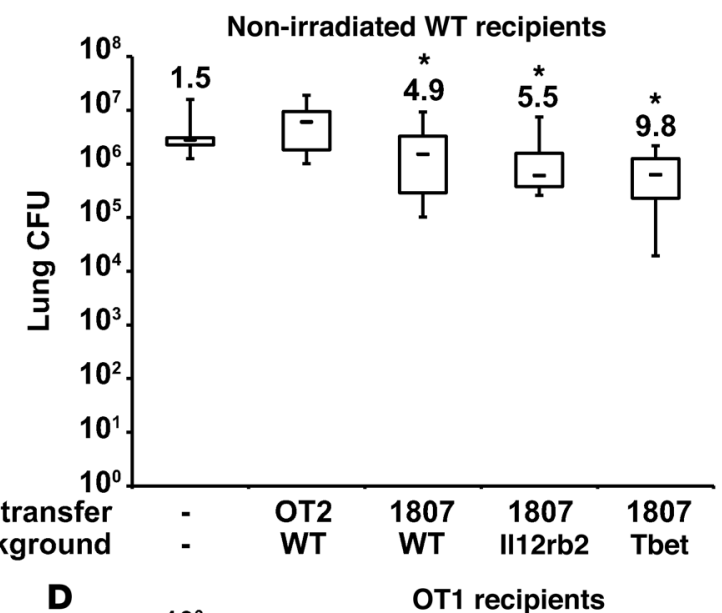

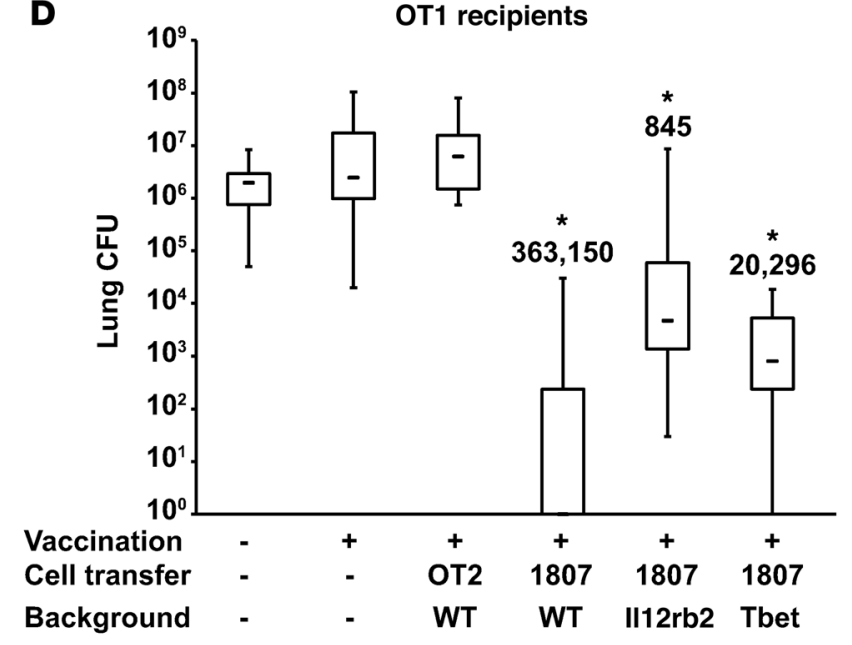

$\mathbf{F}$

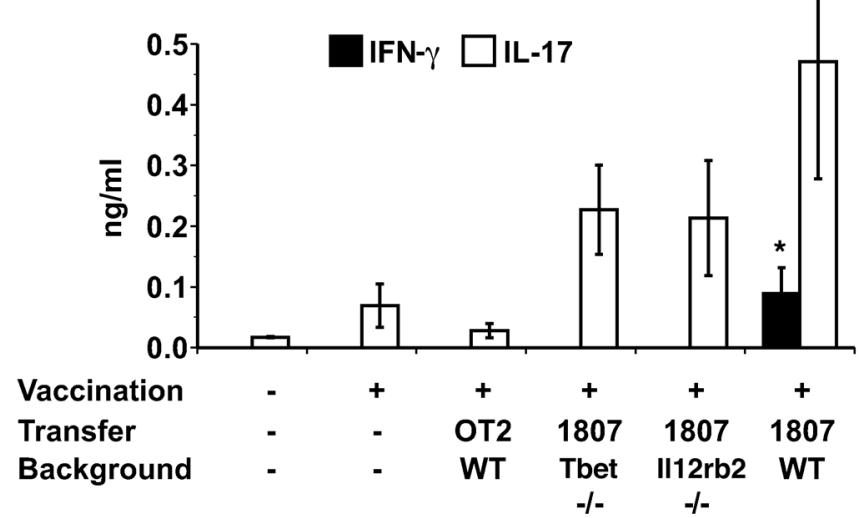

Figure 4

Ag-specific Th17 cells are sufficient to mediate antifungal resistance. (A) Polarization of Th17 cells. The dot plot shows the percentage of IL-17and IFN- $\gamma$-positive CD4+ cells and is representative of all 4 types of TCR Tg T cells (below). (B and C) Transfer of Th17-polarized cells into wild-type recipients. Th17-polarized cells from wild-type $\times 1807, \| / 12 \mathrm{rb2}^{-/-} \times 1807$, Tbet $^{-1} \times 1807$, and OT2 mice were transferred into nonirradiated or sublethally irradiated wild-type mice (78). The next day (nonirradiated recipients) or 8 weeks later (irradiated recipients), mice were challenged with $B$. dermatitidis and analyzed for lung CFU 2 weeks later. Values are the mean \pm SEM $(n=11-18)$. Numbers shown are fold reduction in lung CFU versus OT2 controls. ${ }^{*} P<0.05$ versus OT2 controls. (D) In vivo primed Th17 cells protect vaccinated OT1 mice. $10^{6}$ wild-type $\times 1807, \| 1 / 2 \mathrm{rb2}^{-/-} \times 1807$, and Tbet $^{-1} \times 1807$ cells were transferred into OT1 mice. Recipients were vaccinated, challenged, and analyzed for lung CFU. Values are the mean \pm SEM $(n=9-12)$. Numbers shown are the fold reduction in lung CFU versus OT2 controls. ${ }^{*} P<0.05$ versus unvaccinated mice and vaccinated mice that received OT2 cells. (E) T helper phenotype of in vivo primed $/ 112 \mathrm{rb2} 2^{-/-} \times 1807$ and Tbet $^{-1} \times 1807$ cells. At day 4 after infection, the percentages of cytokine-producing transferred Tg cells were quantified (4-6 mice per group). ${ }^{*} P<0.05$ versus $1807 \times$ Tbet $^{-1}$ and $1807 \times I / 12$ rb2 $^{-1-}$ cells. (F) IL-17 and IFN- $\gamma$ production by splenocytes in response to CW/M Ag in vitro was analyzed; ${ }^{*} P<0.05$ versus all other groups. 


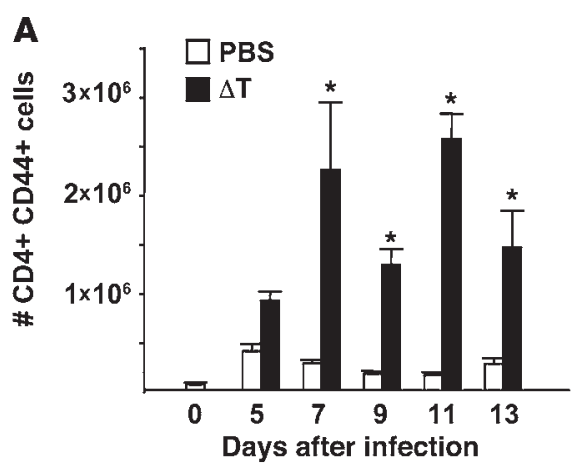

B

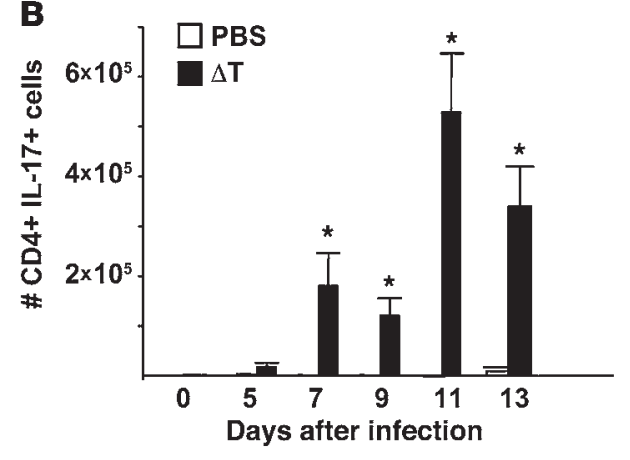

D

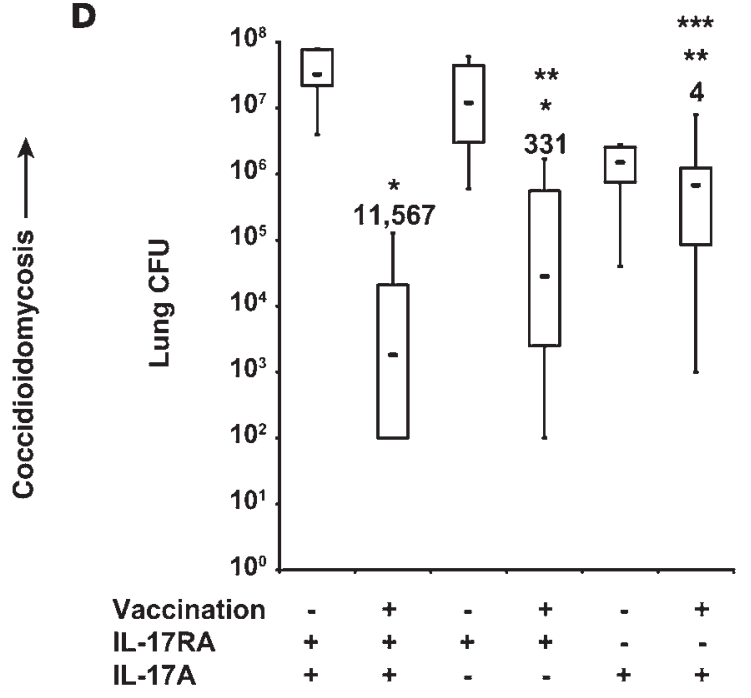

E

a IFN- $\gamma+\mathrm{CD} 4+$ cells $\square$ IL-17+ CD4+ cells

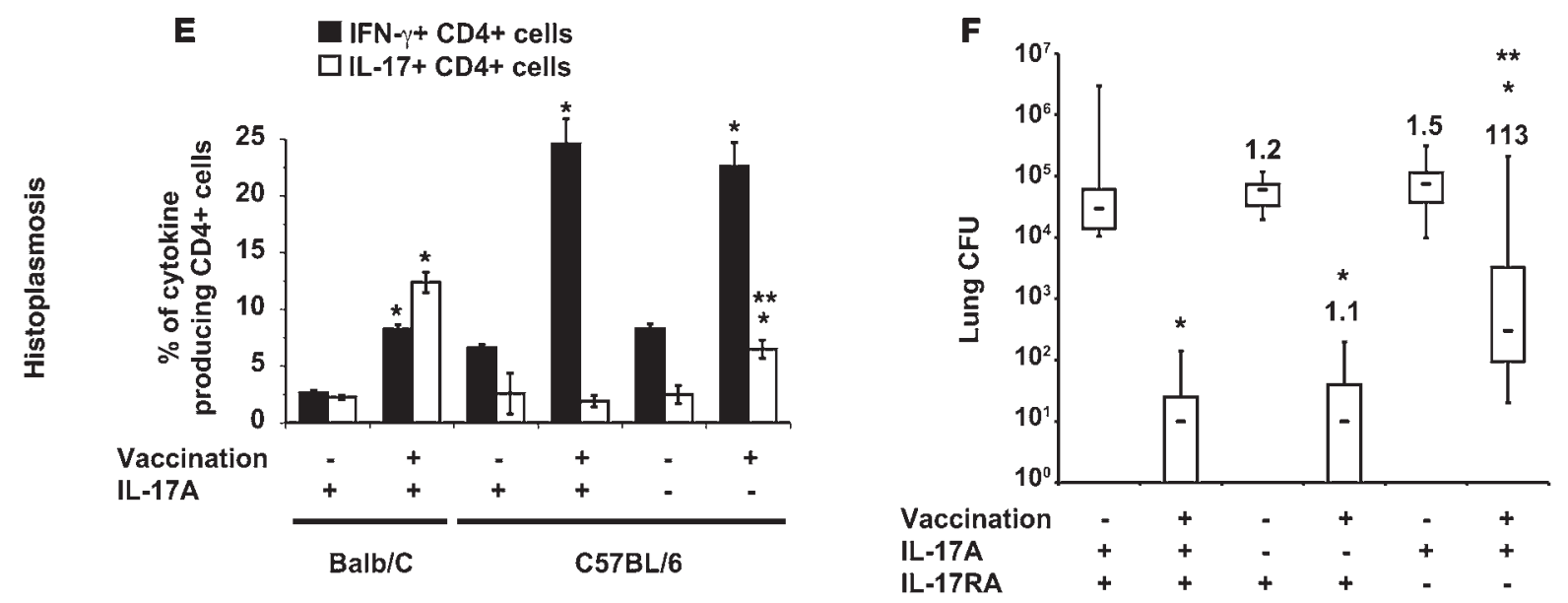

C

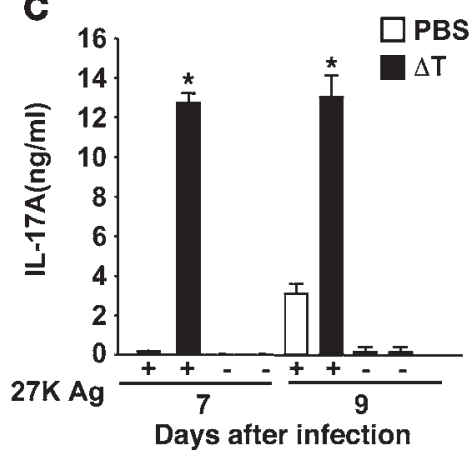

Days after infection

Figure 5

Th17 cells mediate vaccine immunity to multiple dimorphic fungi. (A-D) C. posadasii. C57BL/6 mice were vaccinated with the live attenuated strain $(\Delta \mathrm{T})$ and challenged with $C$. posadasii spores as in Methods. The phenotype of lung CD4 $T$ cells was analyzed serially after infection (A and B). IL-17 production by splenocytes in response to T27K Ag was analyzed in vitro as in Methods (C); ${ }^{*} P<0.05$ versus respective PBS control (A-C). Vaccinated mice were challenged and lung CFU analyzed 2 weeks after infection (D). The numbers shown are fold reduction in CFU versus respective control. ${ }^{*} P<0.001$ versus unvaccinated controls; ${ }^{* \star} P<0.05$ versus vaccinated wild-type mice; ${ }^{* \star \star} P<0.05$ versus vaccinated $/ 117 a^{-/}$mice. (E) H. capsulatum. Balb/C and C57BL/6 mice were vaccinated s.c. and challenged with a sublethal dose of $H$. capsulatum yeast as in Methods. At day 4 after infection, the percentages of IL-17-and IFN- $\gamma$-producing CD4+ $T$ cells were assayed by intracellular cytokine staining and FACS. Data are the mean \pm SEM of 4 mice/group. ${ }^{\star} P<0.01$ versus unvaccinated mice; ${ }^{\star *} P<0.01$ versus vaccinated wild-type mice. (F) C57BL/6 wild-type, $/ / 17 \mathrm{ra}^{-/-}$, and $/ / 17 \mathrm{a}^{-/-}$mice were vaccinated and challenged as in Methods. At day 14 after infection, the mice were sacrificed and analyzed for the burden of lung infection. Data are the mean \pm SEM of 10 to 20 mice per group. ${ }^{*} P<0.01$ versus unvaccinated mice; ${ }^{* *} P<0.01$ versus vaccinated wild-type mice. 
Th17 vaccine immunity recruits and activates $P M N s$ and macrophages to the alveolar space. To clarify how vaccine-induced Th17 cells mediate resistance, we studied the recruitment and activation of phagocytes in the lungs of infected mice. Th17 cells recruit and/or activate PMNs and macrophages to kill Klebsiella pneumoniae $(33,35,43)$ and Bordetella pertussis (44). We studied the perturbations of phagocytes in bronchoalveolar lavage (BAL) fluids of vaccinated $\mathrm{Il17}_{\mathrm{ra}}^{-/-}$and wildtype mice 4 days after infection when the latter had nearly cleared the fungal pathogen (Supplemental Figure 6A). We reasoned that the killing of yeast by recruited and/or activated phagocytes must have occurred at or before this time. The numbers of CD4 T cells were similar in both strains of vaccinated mice at this time point (Supplemental Figure 6B). However, vaccinated $\mathrm{Il}_{17 \mathrm{ra}^{-/-} \text {mice had fewer total }}$ and activated $\left(\mathrm{LFA1}^{+}\right)$PMNs and activated $\left(\mathrm{CD} 11 \mathrm{~b}^{+}\right)$alveolar macrophages than corresponding wild-type mice (Figure 6, A-D, and data not shown). Thus, the influx and activation of leukocyte populations that can kill fungi are reduced in the absence of IL-17 signaling.

To see whether IL-17 augments killing of fungi by phagocytes, we activated PMNs and alveolar macrophages in vitro with rIL-17A or heterodimeric rIL-17A/F and cocultured them with yeast. Homo- and heterodimeric rIL-17 enhanced yeast killing by PMNs and macrophages in an IL-17RA-dependent manner (Figure 6, E and F). To see whether PMNs are linked functionally with vaccine resistance, we depleted these cells with anti-Ly6G $\mathrm{mAb}$ from vaccinated mice during the efferent phase (after infection). At day 4 after infection, lung CFUs were 2-3 logs higher in PMN-depleted mice than rat IgG controls (Figure 6G). Thus, Th17 cells promote vaccine-induced Th17 immunity by recruiting and activating phagocytes in the alveolar space.

Th17 differentiation requires Myd88, but not Dectin-1. The Dectin-1 agonist curdlan (pure $\beta$-glucan) acts as an adjuvant to induce model Ag-specific Th1 and Th17 cells (28), and Dectin-1-activated DCs exposed to $\beta$-glucan convert regulatory T cells into Th17 cells (45). Dectin $1^{-/-}$mice are also susceptible to C. albicans and $P$. carinii in some models $(29,30)$. We tested to determine whether Dectin-1 is required to induce Ag-specific Th17 cells and vaccine immunity to $B$. dermatitidis. Dectin $1^{-/}$mice showed no deficit in vaccine immunity versus wild-type mice (Figure 7A). Neither was Th17 differentiation impaired in vaccinated Dectin $1^{-/-}$mice (Figure 7B) when analyzing lung transcript; the number of lung, polyclonal cytokine-producing CD4 T cells 4 days after infection; and the amount of Ag-specific cytokine made in vitro by CD4 cells. Thus, the development and recruitment of Th17 and Th1 cells was intact in Dectin $1^{-/-}$mice.

To see whether TLRs regulate vaccine-induced Th17 and Th1 responses and resistance, we vaccinated $M y d 88^{-/-}$mice. These mice were unable to control live vaccine (data not shown), so we vaccinated them with killed yeast. Vaccinated $M y d 88^{-/-}$mice failed to acquire resistance and had lung CFUs similar to those of unvaccinated controls (Figure 7B). These mice also failed to recruit primed endogenous T cells or Ag-specific 1807 cells to the lungs (Figure 7D). The number of total polyclonal, IL- $17^{+}$or IFN- $\gamma^{+} \mathrm{CD} 4 \mathrm{~T}$ cells recalled to the lung was similar in vaccinated and unvaccinated $M y d 88^{-/-}$ mice (Figure 7D). CD4 T cells from the draining lymph nodes and spleen of vaccinated $M y d 88^{-/-}$mice did not produce IL-17 or IFN- $\gamma$ in response to Ag stimulation in vitro (Figure 7D). Thus, Myd88 is required for vaccine-induced antifungal Th17 (and Th1) responses.

Besides serving as an adaptor for TLRs, Myd88 is an adaptor for the IL-1R/IL-18R family $(46,47)$ and provides T cell-intrinsic signals required for their function (48). Our finding that T17 dif- ferentiation was severely impaired in wild-type 1807 cells transferred into $M y d 88^{-/-}$mice makes it unlikely that a $\mathrm{T}$ cell intrinsic defect accounts for failed differentiation (Figure 7D). Yet to formally exclude any role for IL-1R or IL-18R signaling as a cause of the MyD88 phenotype, we studied T17 differentiation of wildtype 1807 cells in vivo in recipients lacking IL-1R1 or IL-18R1. After vaccination and challenge, $I l 1 r^{-/}$and $I L 18 r^{-/}$recipients recruited numbers of IL-17-producing 1807 cells (and endogenous, polyclonal $\mathrm{CD}^{+}$cells) to the lungs that were similar to wild-type recipients (Supplemental Figure 7A). Lung CFUs also were reduced to the same extent in all 3 strains of vaccinated mice (Supplemental Figure 7B). Thus, IL-1R and IL-18R are dispensable in the development of T17 cells and vaccine resistance. Moreover, failed T17 differentiation of 1807 cells in $\mathrm{Myd} 88^{-/-}$mice is not due to impaired IL-1R or IL-18R signaling, but is likely due to impaired signaling via TLRs.

\section{Discussion}

The beneficial and detrimental effects of IL-17 and Th17 cells in defending against fungi have been reported in models of primary infections and debated, but the contribution of Th17 cells in vaccine immunity to fungi has received little attention (49). Here, we show that Th17 cells can be engaged by vaccination to confer resistance against multiple dimorphic fungi: C. posadasii, H. capsulatum, and B. dermatitidis. Neutralization of IL-17A with anti-IL-17A $\mathrm{mAb}$, blockade of IL-17A with adenovirus overexpressed soluble IL-17R:Fc, and vaccination of $I l 17 \mathrm{ra}^{-/-}$mice all showed that IL-17A is required for vaccine immunity. Vaccinated $1 l 17 \mathrm{a}^{-/-}$mice showed impaired resistance despite having normal Th1 cell immunity. Because the Th1 products IFN- $\gamma$ and TFN- $\alpha$ are dispensable and compensated by each other during the induction of vaccine immunity (14), we expected that Th1 cytokines would in turn compensate for the loss of IL-17A. Instead, we found that IL-17 is indispensable in vaccine resistance. Resident memory Th17 cells specific for C. albicans have been reported in humans (50) and their role in host defense is supported by the finding that Th17 cells induced by Als3 foster resistance to murine candidiasis (49) and that patients with hyper IgE syndrome are predisposed to mucocutaneous candidiasis (51).

IL-17 primes and recruits protective Th1 cells against intracellular bacteria. In a vaccine model of tuberculosis (37), depletion of IL-17 during challenge reduced chemokine expression and accumulation of IFN- $\gamma$-producing CD4 T cells in the lung. Thus, Th17 cells are thought to recruit Th1 cells to the lung to restrict the growth of M. tuberculosis. In a model of pulmonary tularemia, Th17 cells regulated the generation of $\mathrm{Th} 1$ cells required for protective immunity (38). IL-17A induced IL-12 production in DCs and mediated Th1 responses. Neither IL-17A nor its inducible chemokines protected mice in the absence of the IL-12-Th1 axis, suggesting that Th17 cells alone cannot confer resistance against tularemia. In our fungal models, vaccinated $I l 17 \mathrm{a}^{-/-}$or $I l 17 \mathrm{ra}^{-/-}$mice did not show any reduction in lung IFN- $\gamma$ transcript or in number of IFN- $\gamma$-producing $\mathrm{CD}^{+} \mathrm{T}$ cells after challenge. Thus, IL-17A did not affect the priming or recruitment of protective antifungal Th1 cells to the lung. Th17 cells therefore conferred vaccine resistance in our fungal models by Th1-independent mechanisms.

Th17 cells are also sufficient for vaccine immunity to dimor-

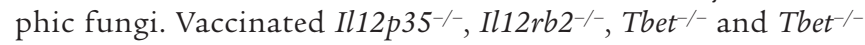
Stat $4^{-/-}$(all B6 background), and Ifng ${ }^{--}$(BALB/c background) mice with impaired Th1 immunity were as protected as wild-type 


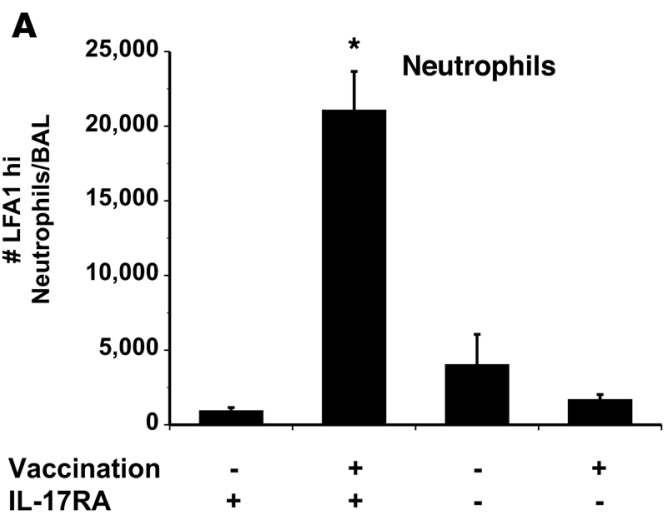

B
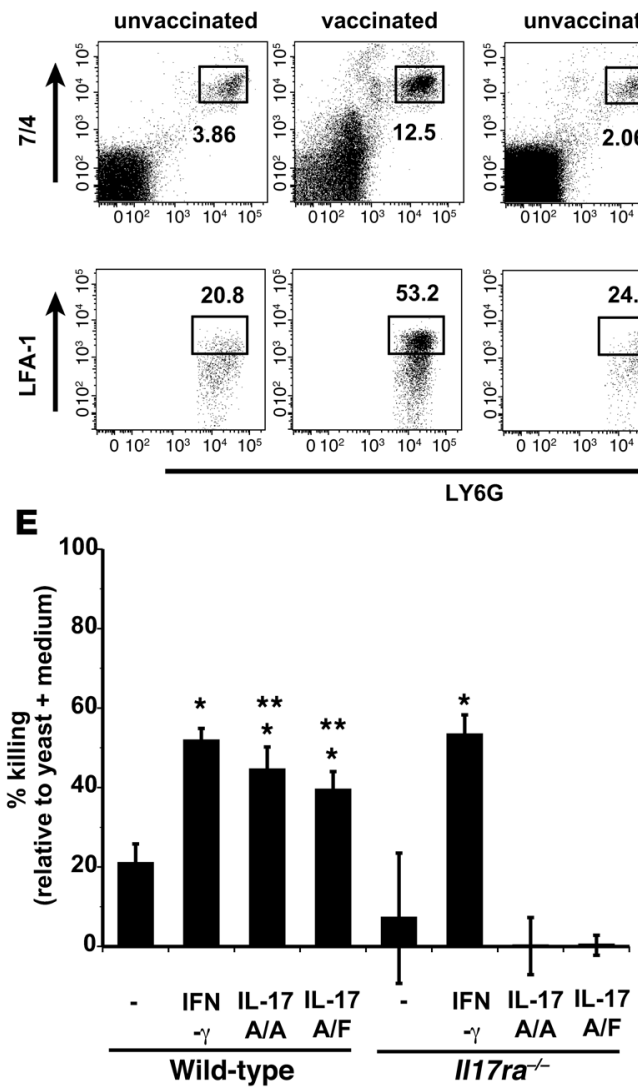

II17ra-1-
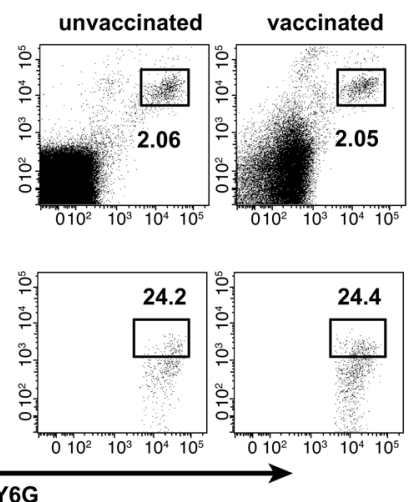

$\mathbf{F}$
C

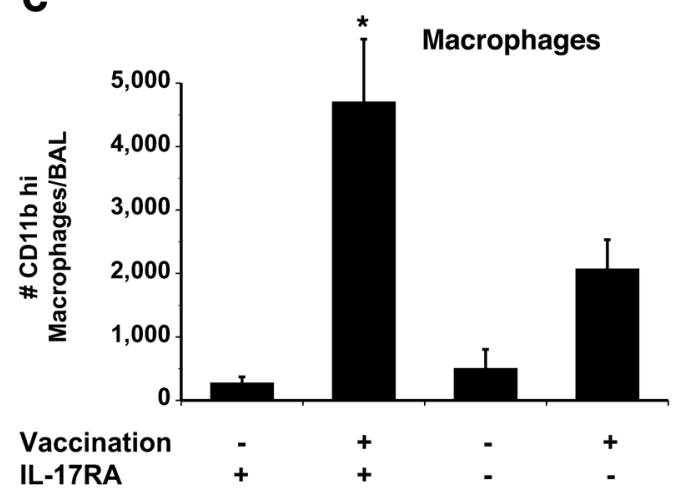

D

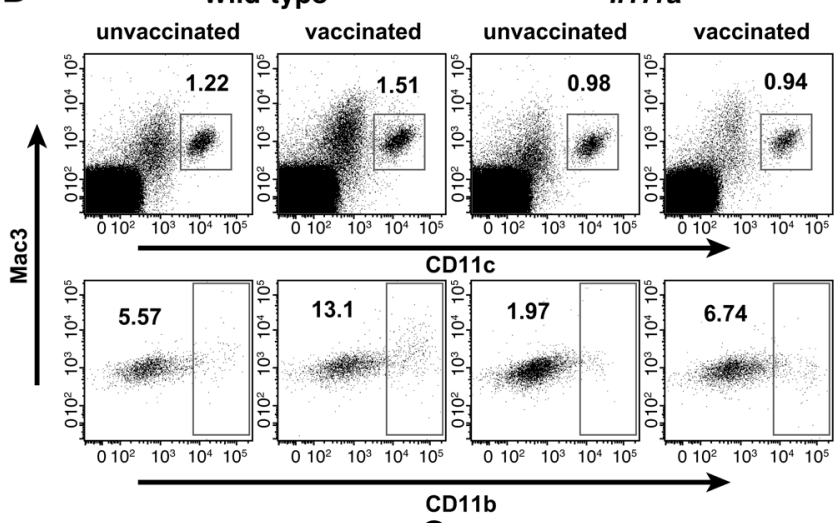

G

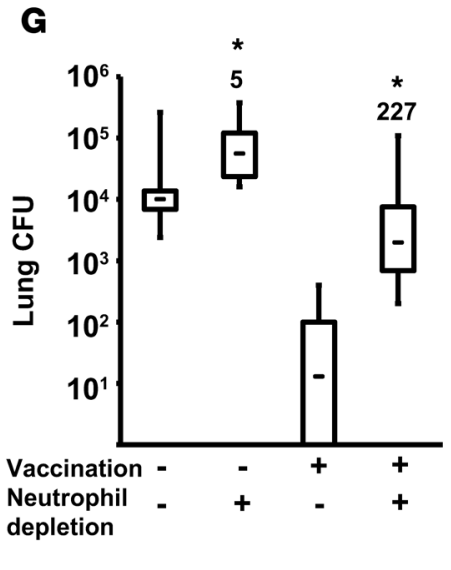

Figure 6

Th17 cells are instrumental in phagocyte recruitment and activation. /117ra--- and wild-type mice were vaccinated with $B$. dermatitidis and challenged. At day 4 after infection, cells from BAL fluid were harvested, enumerated, and stained by FACS. (A) The number of LFA1+ PMNs in BAL; mean \pm SEM of 4-10 mice/group. ${ }^{*} P<0.05$ versus unvaccinated wild-type and vaccinated $/ / 17 \mathrm{ra}^{-/-}$mice. (B) The percentage of LFA1+ $P M N s$ $\left(\mathrm{CD}_{11} \mathrm{~b}^{+}, 7 / 4^{+}\right.$, and Ly6G+) in BAL; mean \pm SEM $(n=4)$. (C) The number of CD11b+ macrophages $\left(\mathrm{CD} 11 \mathrm{C}^{+}\right.$, Mac3 $\left.{ }^{+}\right)$in BAL; mean \pm SEM $(n=4)$. ${ }^{*} P<0.05$ versus unvaccinated wild-type and vaccinated $/ / 17 \mathrm{ra}^{-/-}$mice. (D) The percentage of CD11 $\mathrm{b}^{+}$macrophages (CD11 $\mathrm{C}^{+}$, Mac $\left.3^{+}\right)$in BAL; mean \pm SEM $(n=4)$. (E and F) IL-17-induced killing by neutrophils and alveolar macrophages. Neutrophils and alveolar macrophages from naive wild-type and $/ 17 \mathrm{ra}^{-1-}$ mice were activated with $200 \mathrm{ng} / \mathrm{ml}$ of IFN- $\gamma$, homodimeric IL-17A/A, or heterodimeric IL-17A/F. B. dermatitidis yeast were added to cells at a MOI of 0.01 and cocultured for 4 hours with neutrophils and 24 hours with macrophages. Cell culture supernatants and cell lysates were combined and cultured to enumerate CFU. ${ }^{*} P<0.05$ versus resting neutrophils and macrophages; ${ }^{* *} P<0.05$ versus corresponding cocultures with cells from $/ 117 \mathrm{ra}^{-/}$mice. (G) Influence of neutrophil depletion on vaccine immunity. Neutrophils in vaccinated and unvaccinated wild-type mice were depleted with $250 \mu \mathrm{g}$ of $1 \mathrm{~A} 8 \mathrm{mAb}$ injected i.v. at days 0 and 2 after infection. As a control, mice received rat lgG. At day 4 after infection, lung CFU were enumerated. Data represent an average \pm SEM $(n=10-12)$. ${ }^{*}<0.001$ versus corresponding rat lgG-treated mice. The numbers shown are the fold increase in CFU in neutrophil-depleted versus nondepleted mice. 

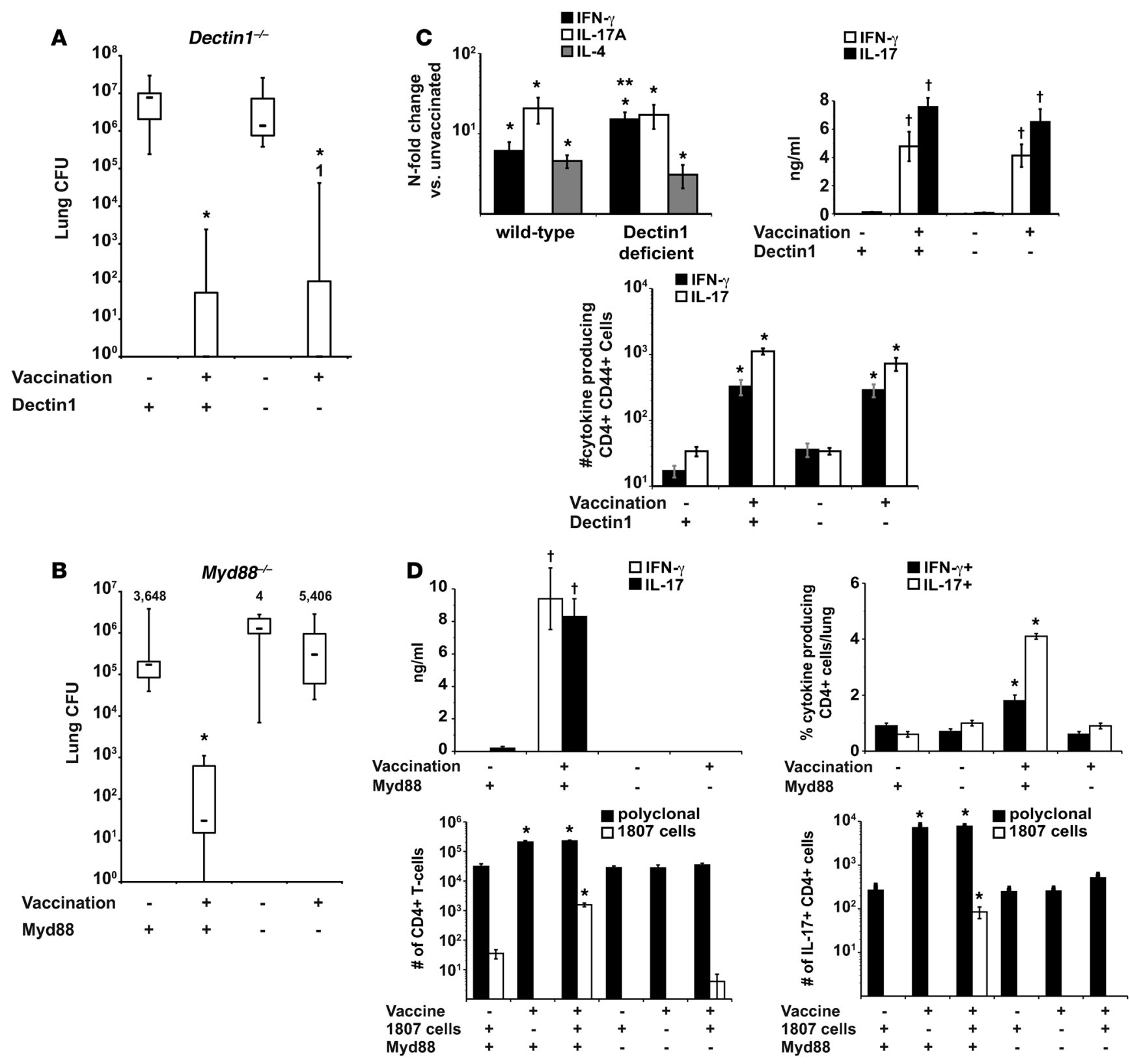

Figure 7

Vaccine-induced resistance is independent of Dectin-1, but dependent on Myd88. (A) Dectin $1^{-/-}$mice and wild-type controls were vaccinated with $B$. dermatitidis. 2 weeks after challenge, mice were analyzed for lung CFU. ${ }^{*} P<0.001$ versus unvaccinated control mice. (B) $M y d 88^{-1-}$ mice and wild-type mice were vaccinated with $10^{6}$ heat-killed yeast. Mice were challenged and 2 weeks later, when the unvaccinated controls were moribund, lung CFU were enumerated. Data are the mean \pm SEM $(n=8-12)$. ${ }^{*} P<0.001$ versus all other groups. (C and D) Lung transcript was analyzed 2 days after infection. RNA was isolated from lung, and transcripts were analyzed by RT-PCR. Data are expressed as fold change versus unvaccinated mice and represent the mean \pm SEM $(n=4-6) .{ }^{*} P<0.05$ versus transcript in unvaccinated controls; ${ }^{* \star} P<0.05$ versus transcript in vaccinated wild-type mice. Intracellular cytokine staining was done at day 3-4 after infection. Lung cells were stained and the absolute numbers of cytokine-producing CD4+ CD44+ T cells determined by FACS. Data represent the mean $\pm \operatorname{SEM}(n=4)$. ${ }^{*} P<0.05$ versus intracellular cytokine in unvaccinated wild-type controls and vaccinated $M y d 88^{-/-}$mice (C and D). To assay Ag-specific cytokine production, CD4+ cells were purified from the skin-draining lymph nodes and spleen and stimulated with CW/M Ag for 2 days. Supernatant was assayed by ELISA. Data are the mean \pm SEM of 4 independent experiments $\left(n=4\right.$ mice/group). ${ }^{t} P<0.001$ versus cytokine production by CD 4 cells from unvaccinated controls or vaccinated $M y d 88^{-1-}$ mice (C and D).

mice. Adoptive transfer of $B$. dermatitidis-specific CD4 cells from 1807 Tg mice, polarized toward a Th17 phenotype, mediated resistance to infection in wild-type mice. Il12rb2-/- $\times 1807$ cells and Tbet $^{/-} \times 1807$ cells transferred into vaccinated OT1 mice expanded more than in wild-type mice and differentiated chiefly into Th17 cells that conferred resistance. Wild-type 1807 cells expressed a balanced Th1/Th17 profile and also protected mice. In vivo primed Th17 cells are therefore sufficient to mediate anti- 
fungal protection. Our findings generated in 2 inbred strains of mice (C57BL/ 6 and BALB/c) do not support the dogma that Th1 cells are required to combat fungal infection $(15,52)$.

Vaccinated mice with polarized Th17 cells appeared healthy after challenge and their lungs were free of aberrant inflammation and tissue damage. These findings contrast with Th17-exacerbated inflammation and infection against gastric C. albicans and pulmonary A. fumigatus infection (23). There, IL-23 and IL-17 subverted the inflammatory program of PMNs, which produced tissue inflammatory pathology associated with infection. Despite a formidable proinflammatory program, Th17 cells may be largely beneficial in our vaccine models due to their rapid lung entry upon recall, and the resulting positive balance of Th17 cells versus fungal inoculum, allowing for rapid clearance of infection before chronic inflammation.

Since Th17 cells were sufficient for vaccine resistance and did not mediate protection by inducing and recruiting Th1 cells to the lung, we explored other mechanisms. IL-17 (A/A, F/F, and A/F) produced by Th17 cells regulates the induction of CXC chemokines in fibroblasts and bronchial epithelial cells, which recruit PMNs into the airways $(35,53-56)$. Loss of IL-17RA signaling or depletion of Th17 cells ablates the expression of chemokines and recruitment of PMNs and impairs host defense against $K$. pneumoniae and M. tuberculosis $(33,37)$. IL-17A also activates macrophages to kill B. pertussis (44). In our vaccine model, the recruitment of activated PMNs and macrophages to the alveoli was constrained in the absence of IL-17A signaling. Depletion of PMNs during the efferent phase abolished vaccine immunity. Activation of alveolar macrophages and PMNs by IL-17A/A and IL-17A/F in vitro augmented fungal killing, suggesting that antifungal Th17 cells confer protection by recruiting and activating these phagocytes. However, we cannot exclude the possibility that other myeloid or nonmyeloid cells could also be targets of vaccine-induced IL-17 signaling $(57,58)$.

Dectin-1 is reportedly required for inducing Th17 responses to fungal infections $(22,28,59)$. In the absence of Dectin-1, the production of IL-17 and other inflammatory mediators is reduced in the lungs of A. fumigatus-infected mice and killing by phagocytes impaired (22). Dectin $1^{-/}$mice are vulnerable to primary pulmonary infection with A. fumigatus, C. albicans, and P. carinii $(22,29,30)$. In contrast, Dectin-1 is unexpectedly dispensable in the development of vaccine-induced Th17 cell responses and resistance to fungi in our study.

Myd88 instead had a profound role in inducing Th17 respons-

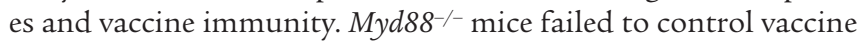
yeast in the skin or recruit primed Ag-specific Th17 and Th1 cells (endogenous and $\mathrm{Tg}$ ) to the lung to combat fungal infection. Since Myd88 mediates not only TLR signals, but also those via IL-1R and IL-18R, impaired Th17 cell priming and recruitment could be related to the latter defects in signaling $(47,60)$. The fact that adoptively transferred wild-type 1807 cells failed to recruit to the lung in $\mathrm{Myd88^{-/- }}$ mice, but showed no deficit in $\mathrm{Il}^{-/-}$and $I l 18 r^{-1-}$ mice, indicates that the deficits in $M y d 88^{-/-}$mice are not due to impaired IL-1R or IL-18R signaling, but are likely due to impaired signaling via TLRs.

In Aspergillus infection, the initial priming of CD4 T cells in the mediastinal lymph nodes and their entry and differentiation in the lungs is independent of Myd88 (61), although Myd88 does regulate the early differentiation of these cells in the draining nodes. The different cell wall composition of $A$. fumigatus and B. dermatitidis may explain the differences in these studies. $\beta$-glucan on
A. fumigatus conidia regulates Dectin-1 recognition, whereas other ligands may be important for Myd88-dependent signaling on B. dermatitidis and the other systemic dimorphic fungi.

\section{Methods}

Mouse strains. Inbred strains of mice on the C57BL/6 background were used for this work unless otherwise stated and obtained from Jackson Laboratories. The strains included wild-type C57BL/6, T lymphocyte-specific Thy 1.1 allele carrying congenic B6 strain B6.PL-Thy1a/Cy (stock 000406) (62), Il12p35-/- B6.129S1-Ill2a $a^{\text {tm1Jm} / J ~(s t o c k ~ 002692) ~(63), ~ I l 12 / 23 p 40-/-~ B 6.129 S 1-~}$ Il12 $b^{\text {tmIIJm} / J ~(s t o c k ~} 002693$ (64), Il12rb2-/- B6.129S1-Il12r $\beta 2^{\text {tmIIJm} / J ~ m i c e ~(s t o c k ~}$ 3248) (65), Tbet $/-$ B6.129S6-Tbx21 $1^{\text {tm } 1 \text { Glm }} / \mathrm{J}$ mice (stock 004648) (66), Illr1 $1^{-/-}$ B6.129S7-Il1r1 $1^{\text {tm IImx }} / \mathrm{J}$ mice (stock 003245) (67), and Il18r1 $1^{-/-}$B6.129P2-

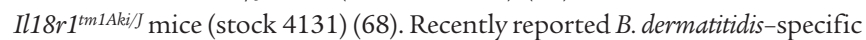
1807 TCR Tg mice (Wüthrich et al., unpublished observations) were crossed

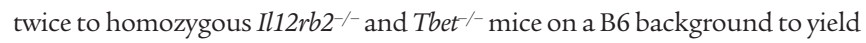
1807 TCR Tg mice that lack IL-12R $\beta 2$ or T-bet. Breeder pairs for IL17 $\mathrm{ra}^{-/-}$ (33), Il17a $a^{-/}$(69) and Tbet $/-$Stat4 ${ }^{-/-}$mice (70) were provided by Amgen, Jay Kolls (University of Pittsburgh, Pittsburgh, Pennsylvania, USA), and Mark

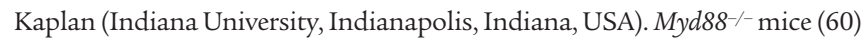
were provided by Doug Golenbock and Stuart Levitz (University of Massachusetts, Worcester, Massachusetts, USA). To extend our findings with C57BL/6 mice, we also studied mice from Jackson Laboratories on a BALB/c background: wild-type and Ifng ${ }^{-/}$C.129S7(B6)-Ifng $g^{\text {tmiTs }} / \mathrm{J}$ (stock \#002286). All mice were 7-8 weeks of age at the time of experiments. Mice were housed and cared for according to guidelines of the University of Wisconsin Animal Care Committee, who approved all aspects of this work.

Fungi. B. dermatitidis strains used were ATCC 26199 (71), a wild-type virulent strain, and the isogenic, attenuated mutant lacking BAD1, designated strain 55 (72). Isolates of $B$. dermatitidis were maintained as yeast on Middlebrook 7H10 agar with oleic acid-albumin complex (Sigma-Aldrich) at $39^{\circ}$ C. H. capsulatum strain G217B was maintained on Histoplasma Macrophage Medium (HMM) plates. C. posadasii isolate $\mathrm{C} 735$ is a virulent, human clinical strain that was used to generate a live, attenuated vaccine strain $(\Delta \mathrm{T})$ by deleting the chitinases 2,3 , and $\mathrm{D}$-arabinotol-2-dehydrogenase genes as previously described (9). The saprobic phase of both the parental and mutant strains were grown on GYE medium ( $1 \%$ glucose, $0.5 \%$ yeast extract, $1.5 \%$ agar) at $30^{\circ} \mathrm{C}$ for 3 to 4 weeks to generate a confluent layer of arthroconidia (spores) on the agar surface.

Generation of in vitro-stimulated Th17 effector 1807 cells. IL-17-producing TCR Tg effector CD4 cells were generated by adding naive, magnetic beadpurified CD4 cells from 1807 mice on plate-bound anti-CD3 $(2 \mu \mathrm{g} / \mathrm{ml})$ (BD Bioscience) with soluble anti-CD28 $(5 \mu \mathrm{g} / \mathrm{ml})$ in the presence or absence of human recombinant IL-6 (30 ng/ml) (206-IL; R\&D), human recombinant TGF- $\beta(1 \mathrm{ng} / \mathrm{ml})(240-\mathrm{B} / \mathrm{CF}$; R\&D), rat anti-mouse IL-4 mAb (clone 1B11, $10 \mu \mathrm{g} / \mathrm{ml}$ ), and anti-IFN- $\gamma \mathrm{mAb}(10 \mu \mathrm{g} / \mathrm{ml})$ (NCI Biological Research Branch) for 5 days at $37^{\circ} \mathrm{C}$ and $5 \% \mathrm{CO}_{2}$. The culture medium used was IMDM (16529; Sigma-Aldrich) supplemented with $2 \times 10^{-3} \mathrm{M}$ L-glutamine, $100 \mathrm{U} / \mathrm{ml}$ penicillin, $100 \mu \mathrm{g} / \mathrm{ml}$ streptomycin, $5 \times 10^{-5} \mathrm{M}$ $\beta$-mercaptoethanol, and 5\% FCS (73). $2 \times 10^{7}$ effector TCR Tg cells were transferred i.v. into nonirradiated or sublethally irradiated (5.5 Gy) C57BL/6 mice. Irradiated mice were rested for 10 weeks before infection.

Vaccination and experimental fungal infection. Mice were vaccinated with B. dermatitidis as described (11) twice, 2 weeks apart, each time receiving a s.c. injection of $10^{5}$ attenuated vaccine strain 55 yeast at each of 2 sites, dorsally and at the base of the tail, unless otherwise stated. Mice were infected intratracheally (i.t.) with $2 \times 10^{3}$ isogenic wild-type 26199 B. dermatitidis yeast as described (11). Infected mice were analyzed 2 weeks after infection for extent of lung infection, determined by plating of homogenized lung and enumeration of yeast CFU on brain heart infusion (BHI) (Difco) agar. 
Mice were vaccinated with $H$. capsulatum as described (10) twice, 2 weeks apart, each time receiving a s.c. injection of $10^{6} \mathrm{G} 217 \mathrm{~B}$ yeast at each of 2 sites, dorsally and at the base of the tail. To prevent hypersensitivity of the vaccinated mice, they were rested 8 to 10 weeks before pulmonary challenge. Mice were challenged with a sublethal dose of $10^{5} \mathrm{G} 217 \mathrm{~B}$ i.t. The lung burden was determined 14 days later by plating lung homogenates on sheep blood containing Mycosel plates to enumerate lung CFU.

Mice were vaccinated and challenged with C. posadasii as reported (9). Mice were immunized s.c. in the abdominal region with $5.0 \times 10^{4}$ viable spores of the $\Delta T$ strain (9). The spores were suspended in $100 \mu l$ PBS. Primary immunization was followed 14 days later with an immunization boost of $2.5 \times 10^{4}$ live spores. Unvaccinated control mice were injected s.c. with $\mathrm{PBS}$ alone using the same temporal sequence as employed above. The vaccinated and control mice were challenged by the intranasal route with a potentially lethal dose of spores (50-80 viable cells) isolated from the virulent, parental strain 4 weeks after completion of the vaccination protocol (12). The fungal burden determined as CFU in lungs and spleen of the vaccinated and unvaccinated mice was conducted at 14 days after infection by plating serial dilutions of the respective organ homogenates on GYE plates containing $50 \mu \mathrm{g} / \mathrm{ml}$ of chloramphenicol.

Isolation of effector T cells from the site of vaccination. Inflamed s.c. tissue was excised from the site of vaccination, placed into ice-cold PBS, minced into fine pieces, and digested with 0.28 Wench units Liberase Blendzyme 3 (184184; Roche Diagnostics) at $37^{\circ} \mathrm{C} / 5 \% \mathrm{CO}_{2}$ for 30 minutes. To further release single cells, the tissue was mashed with the back of a $10-\mathrm{ml}$ syringe plunger, and DNAse I was added to a final concentration of $50 \mu \mathrm{g} / \mathrm{ml}$ (Sigma-Aldrich) and incubated for another 30 minutes. The dissolved tissue and cells were pipetted up and down 5 times and filtered through a $70-\mu \mathrm{M}$ cell strainer. The filtered cells were spun down at $500 \mathrm{~g}$ for 5 minutes with no brake. The supernatant was carefully aspirated. The pellet was resuspended in $10 \mathrm{ml}$ PBS and spun down again to wash the cells and yield a firm pellet that was resuspended in complete media for stimulation or surface staining.

Intracellular cytokine staining. Skin-tissue-derived cells were harvested at serial time points after vaccination, and lung cells from individual mice were harvested at day 3-4 after infection. The isolated cells $\left(0.5 \times 10^{6}\right.$ cells $\left./ \mathrm{ml}\right)$ were stimulated for 4 hours with anti-CD3 (clone 145-2C11;0.1 $\mathrm{\mu g} / \mathrm{ml}$ ) and anti-CD28 (clone $37.51 ; 1 \mu \mathrm{g} / \mathrm{ml}$ ) in the presence of Golgi-Stop (BD Biosciences) to halt egress of cytokines from the cells. After cells were washed and stained for surface CD4 and CD8 using anti-CD4 PeCy7, anti-CD8 PerCp, anti-CD44-FITC, and anti-CD62L PE mAbs (BD Biosciences - Pharmingen), they were fixed and permeabilized in Cytofix/Cytoperm at $4^{\circ} \mathrm{C}$ overnight. Permeabilized cells were stained with anti-IFN- $\gamma$ Alexa Fluor 700 (clone XMG1.2), anti-IL-17 PE (clone TC11-18H10), and anti-IL-13 Alexa Fluor 647-conjugated (51-7133) mAbs (BD Biosciences - Pharmingen and Ebioscience) in FACS buffer for 30 minutes at $4^{\circ} \mathrm{C}$, washed, and analyzed by FACS. Lymphocytes were gated on CD 4 or CD8 and CD $44^{\text {hi }}$, and cytokine expression in each gate was analyzed. The number of cytokineproducing $\mathrm{CD}^{+}$and $\mathrm{CD}^{+} \mathrm{T}$ cells per lung was calculated by multiplying the percentage of cytokine-producing cells by the number of $\mathrm{CD}^{+}$and $\mathrm{CD}^{+}$cells in the lung.

In vivo neutralization of IL-17 and IFN- $\gamma$. To neutralize IL-17 in animals, we treated mice either with anti-IL-17 mAb or infected them with recombinant adenovirus expressing soluble IL-17 receptor. We injected $250 \mu \mathrm{g}$ of anti-IL-17A mAb (M210 generously provided by Amgen) i.v. every other day during the efferent phase of vaccine immunity starting at day 0 after pulmonary infection. To neutralize IL-17 with the soluble receptor, mice were infected i.t. and/or i.v. with 2.4 to $4 \times 10^{9} \mathrm{PFU}$ of AdIL-17RA or AdLuc (control virus expressing luciferase) (provided by Jay Kolls and propagated by the Vector Core lab at the University of Michigan, Ann Arbor, Michi- gan, USA). Injection of AdLuc did not yield detectable levels of soluble IL-17 receptor by Western blot, whereas AdIL-17RA did (data not shown). For maximal expression, we injected the recombinant adenovirus i.v. at days -3 and -1 before challenge and i.t. as a cochallenge with 26199 yeast at day 0 . To neutralize IFN- $\gamma$, mice were given $250 \mu \mathrm{g}$ of XMG1.2 mAb i.v. (purified from ascites), and controls were given $250 \mu \mathrm{g}$ of rat IgG (SigmaAldrich) by a similar schedule.

Cytokine protein measurements. Cell culture supernatants were generated in 24-well plates in $1 \mathrm{ml}$ containing $5 \times 10^{6}$ splenocytes and lymph node cells and $12.5 \mu \mathrm{g} / \mathrm{ml}$ of $B$. dermatitidis yeast cell-wall/membrane (CW/M) $\mathrm{Ag}$ (11). CW/M Ag contained less than 0.1 endotoxin unit $/ \mathrm{ml}$. Supernatants were collected after 96 hours of coculture. IFN- $\gamma$, IL-17, and IL-13 (R\&D System) were measured by ELISA according to manufacturer specifications (detection limits were $0.05 \mathrm{ng} / \mathrm{ml}, 0.02 \mathrm{ng} / \mathrm{ml}$, and $0.05 \mathrm{ng} / \mathrm{ml}$, respectively).

FACS analysis of phagocyte populations in BAL fluid. $10 \mathrm{ml}$ of BAL fluids was harvested from each mouse by repetitive instillation of $1 \mathrm{ml}$ cold PBS containing $0.05 \%$ EDTA and kept on ice. Cells from BAL fluid were resuspended in flow cytometry buffer containing $0.5 \%$ BSA and $2 \mathrm{mM}$ EDTA and stained with the appropriate antibody cocktails. To analyze alveolar macrophages, we used a cocktail of antibodies containing Pacific Blue Live/Dead stain, CD11c-APC, CD11b-PECy7, MHC II-FITC, and Mac3-PE; and for neutrophils we used Pacific Blue Live/Dead stain, Ly6G-FiTC, 7/4-biotin (74) with streptavidin PerCPCy5, CD11b-APC, and LFA1-PECy7.

Ex vivo macrophage-and neutrophil-killing assays. Alveolar macrophages from the BAL fluids and neutrophils from the peritoneum were harvested (75) and resuspended in complete RPMI and plated in 96-well plates at a concentration of $10^{5}$ cells/well and $4 \times 10^{5}$ cells/well, respectively. For macrophages after a 3 -hour incubation, at $37^{\circ} \mathrm{C}$ and $5 \% \mathrm{CO}_{2}$, the nonadherent cells were washed away. For neutrophils, nonadherent cells were harvested after 2 hours of incubation. Macrophages and neutrophil monolayers were incubated overnight in complete medium alone or medium plus $100 \mathrm{U} / \mathrm{ml}$ of recombinant IFN- $\gamma, 200 \mathrm{ng} / \mathrm{ml}$ of recombinant IL-17 A/A homodimer (R\&D Systems), or $200 \mathrm{ng} / \mathrm{ml}$ of IL-17 A/F heterodimer (R\&D Systems). B. dermatitidis yeast were added to the monolayers at a MOI of 0.01 . This concentration of IL- 17 was chosen after preliminary studies using $25-200 \mathrm{ng} / \mathrm{ml}$ showed concentration-dependent growth inhibition of yeast that peaked at $200 \mathrm{ng} / \mathrm{ml}$. The cocultures were incubated for 4 hours (neutrophils) and 24 hours (macrophages) at $37^{\circ} \mathrm{C}$ and $5 \% \mathrm{CO}_{2}$. Supernatants were harvested, and cells were lysed with $250 \mathrm{ml}$ of sterile water. Lysates were combined with supernatants, passed through a 22-gauge needle to disrupt any clumps of yeast, and plated on BHI agar. Colonies were counted after 1 week of incubation at $37^{\circ} \mathrm{C}$ without $\mathrm{CO}_{2}$.

Neutrophil depletion. Vaccinated and unvaccinated mice were treated i.v. with $250 \mu \mathrm{g}$ of anti-Ly6G mAb (1A8) (BioXCell) $(76,77)$ on the day of challenge and 2 days after infection. Depletion was confirmed by FACS analysis of cells in the lung homogenates. As a control, mice were treated with similar amounts of rat IgG (Sigma-Aldrich).

Statistics. The number of cytokine-producing $\mathrm{CD} 4^{+}$and $\mathrm{CD} 8^{+} \mathrm{T}$ cells, the relative changes in cytokine transcripts, and the differences in number of CFU were compared among groups using ANOVA models (78). Outcome measures were logarithmically transformed for analysis where appropriate. A 2 -sided $P$ value of less than 0.05 was considered statistically significant.

\section{Acknowledgments}

This work was supported by grants R21 AI076700 (to M. Wüthrich), R01 AI40996-10 (to B. Klein), and R01 AI 071118 (to G. Cole). We 
thank Marulasiddappa Suresh from the Department of Pathobiological Sciences at the University of Wisconsin School of Veterinary Medicine for helpful discussions; and Bob Gordon from the department of Pediatrics for assistance with graphic illustrations. We also thank Natalia Castro-Lopez and Michael J. Bellecourt for their technical assistance in determinations of fungal burden in the C. posadasii-infected mice.
Received for publication June 10, 2010, and accepted in revised form November 3, 2010.

Address correspondence to: Marcel Wüthrich, University of Wisconsin, Microbial Sciences Building, 1550 Linden Drive, Madison, Wisconsin 53706, USA. Phone: 608.262.7703; Fax: 608.262.8418; E-mail: mwuethri@wisc.edu.
1. Pulendran B, Seder RA. Host-pathogen interactions in the 21st century. Curr Opin Immunol. 2005; 17(4):335-337.

2. Cutler JE, Deepe GS Jr, Klein BS. Advances in combating fungal diseases: vaccines on the threshold. Nat Rev Microbiol. 2007;5(1):13-28.

3. Mochon $\mathrm{AB}$, Cutler JE. Is a vaccine needed against Candida albicans? Med Mycol. 2005;43(2):97-115.

4. Deepe GS Jr, Wuthrich M, Klein BS. Progress in vaccination for histoplasmosis and blastomycosis: coping with cellular immunity. Med Mycol. 2005;43(5):381-389.

5. Cole GT, et al. A vaccine against coccidioidomycosis is justified and attainable. Med Mycol. 2004;42(3):189-216.

6. Deepe GS Jr. Preventative and therapeutic vaccines for fungal infections: from concept to implementation. Expert Rev Vaccines. 2004;3(6):701-709.

7. Casadevall A, Pirofski LA. Feasibility and prospects for a vaccine to prevent cryptococcosis. Med Mycol. 2005;43(8):667-680.

8. Feldmesser M. Prospects of vaccines for invasive aspergillosis. Med Mycol. 2005;43(7):571-587.

9. Xue J, Chen X, Selby D, Hung CY, Yu JJ, Cole GT. A genetically engineered live attenuated vaccine of Coccidioides posadasii protects BALB/c mice against coccidioidomycosis. Infect Immun. 2009; 77(8):3196-3208.

10. Wüthrich M, Filutowicz HI, Warner T, Deepe GS $\mathrm{Jr}$, Klein BS. Vaccine immunity to pathogenic fungi overcomes the requirement for CD4 help in exogenous antigen presentation to CD8+ T cells: implications for vaccine development in immune-deficient hosts. J Exp Med. 2003;197(11):1405-1416.

11. Wüthrich M, Filutowicz HI, Klein BS. Mutation of the WI-1 gene yields an attenuated Blastomyces dermatitidis strain that induces host resistance. J Clin Invest. 2000;106(11):1381-1389.

12. Pfaller MA, Diekema DJ. Epidemiology of invasive mycoses in North America. Crit Rev Microbiol. 2010;36(1):1-53.

13. Allendorfer R, Brunner GD, Deepe GS Jr. Complex requirements for nascent and memory immunity in pulmonary histoplasmosis. J Immunol. 1999; 162(12):7389-7396.

14. Wüthrich M, Filutowicz HI, Warner T, Klein BS, Requisite elements in vaccine immunity to Blastomyces dermatitidis: plasticity uncovers vaccine potential in immune-deficient hosts. J Immunol. 2002; 169(12):6969-6976.

15. Romani L. Immunity to fungal infections. Nat Rev Immunol. 2004;4(1):1-23.

16. Wüthrich M, Warner T, Klein BS. IL-12 is required for induction but not maintenance of protective, memory responses to blastomyces dermatitidis: implications for vaccine development in immunedeficient hosts. J Immunol. 2005;175(8):5288-5297.

17. Romani L, Puccetti P, Bistoni F. Interleukin-12 in infectious diseases. Clinical Microbiology Reviews. 1997;10(4):611-636.

18. Huang W, Na L, Fidel PL, Schwarzenberger P. Requirement of interleukin-17A for systemic antiCandida albicans host defense in mice. J Infect Dis. 2004;190(3):624-631

19. Conti HR, et al. Th17 cells and IL-17 receptor signaling are essential for mucosal host defense against oral candidiasis. J Exp Med. 2009;206(2):299-311.

20. Rudner XL, Happel KI, Young EA, Shellito JE. Inter- leukin-23 (IL-23)-IL-17 cytokine axis in murine Pneumocystis carinii infection. Infect Immun. 2007;75(6):3055-3061.

21. Deepe GS Jr, Gibbons RS. Interleukins 17 and 23 influence the host response to Histoplasma capsulatum. J Infect Dis. 2009;200(1):142-151.

22 . Werner JL, et al. Requisite role for the dectin1 beta-glucan receptor in pulmonary defense against Aspergillus fumigatus. J Immunol. 2009; 182(8):4938-4946.

23. Zelante T, et al. IL-23 and the Th17 pathway promote inflammation and impair antifungal immune resistance. Eur J Immunol. 2007;37(10):2695-2706.

24. Rogers NC, et al. Syk-dependent cytokine induction by Dectin- 1 reveals a novel pattern recognition pathway for $\mathrm{C}$ type lectins. Immunity. 2005; 22(4):507-517.

25. Underhill DM, Rossnagle E, Lowell CA, Simmons RM. Dectin-1 activates Syk tyrosine kinase in a dynamic subset of macrophages for reactive oxygen production. Blood. 2005;106(7):2543-2550.

26. Gross O, et al. Card9 controls a non-TLR signalling pathway for innate anti-fungal immunity. Nature. 2006; 442(7103):651-656.

27. Goodridge HS, Simmons RM, Underhill DM. Dectin-1 stimulation by Candida albicans yeast or zymosan triggers NFAT activation in macrophages and dendritic cells. J Immunol. 2007;178(5):3107-3115.

28. LeibundGut-Landmann S, et al. Syk- and CARD9dependent coupling of innate immunity to the induction of $\mathrm{T}$ helper cells that produce interleukin 17. Nat Immunol. 2007;8(6):630-638.

29. Taylor PR, et al. Dectin-1 is required for beta-glucan recognition and control of fungal infection. Nat Immunol. 2007;8(1):31-38.

30. Saijo S, et al. Dectin-1 is required for host defense against Pneumocystis carinii but not against Candida albicans. Nat Immunol. 2007;8(1):39-46.

31. Kleinschek MA, et al. IL-23 enhances the inflammatory cell response in Cryptococcus neoformans infection and induces a cytokine pattern distinct from IL-12. J Immunol. 2006;176(2):1098-1106.

32. Forlow SB, Schurr JR, Kolls JK, Bagby GJ, Schwarzenberger PO, Ley K. Increased granulopoiesis through interleukin-17 and granulocyte colonystimulating factor in leukocyte adhesion moleculedeficient mice. Blood. 2001;98(12):3309-3314.

33. Ye P, et al. Requirement of interleukin 17 receptor signaling for lung CXC chemokine and granulocyte colony-stimulating factor expression, neutrophil recruitment, and host defense. J Exp Med. 2001;194(4):519-527.

34. Tan W, Huang W, Zhong Q, Schwarzenberger P. IL-17 receptor knockout mice have enhanced myelotoxicity and impaired hemopoietic recovery following gamma irradiation. J Immunol. 2006; 176(10):6186-6193

35. Liang SC, et al. An IL-17F/A heterodimer protein is produced by mouse Th17 cells and induces airway neutrophil recruitment. J Immunol. 2007; 179(11):7791-7799.

36. Ouyang W, Kolls JK, Zheng Y. The biological functions of $\mathrm{T}$ helper 17 cell effector cytokines in inflammation. Immunity. 2008;28(4):454-467.

37. Khader SA, et al. IL-23 and IL-17 in the establishment of protective pulmonary CD $4+\mathrm{T}$ cell responses after vaccination and during Mycobacterium tuberculosis challenge. Nat Immunol. 2007;
8(4):369-377.

38. Lin Y, et al. Interleukin-17 is required for T helper 1 cell immunity and host resistance to the intracellular pathogen Francisella tularensis. Immunity. 2009;31(5):799-810.

39. Usui T, Nishikomori R, Kitani A, Strober W. GATA-3 suppresses Th1 development by downregulation of Stat 4 and not through effects on IL-12Rbeta2 chain or T-bet. Immunity. 2003;18(3):415-428.

40. Mullen AC, et al. Role of T-bet in commitment of TH1 cells before IL-12-dependent selection. Science. 2001;292(5523):1907-1910.

41. Nurieva R, Yang XO, Chung Y, Dong C. Cutting edge: in vitro generated Th17 cells maintain their cytokine expression program in normal but not lymphopenic hosts. J Immunol. 2009;182(5):2565-2568.

42. Zimmermann CR, Johnson SM, Martens GW, White AG, Zimmer BL, Pappagianis D. Protection against lethal murine coccidioidomycosis by a soluble vaccine from spherules. Infect Immun. 1998;66(5):2342-2345.

43. Happel KI, et al. Divergent roles of IL-23 and IL-12 in host defense against Klebsiella pneumoniae. J Exp Med. 2005;202(6):761-769.

44. Higgins SC, Jarnicki AG, Lavelle EC, Mills KH. TLR4 mediates vaccine-induced protective cellular immunity to Bordetella pertussis: role of IL-17-producing T cells. J Immunol. 2006;177(11):7980-7989.

45. Osorio F, et al. DC activated via dectin-1 convert Treg into IL-17 producers. Eur J Immunol. 2008; 38(12):3274-3281.

46. Chung Y, et al. Critical regulation of early Th17 cell differentiation by interleukin-1 signaling. Immunity. 2009;30(4):576-587.

47. Gutcher I, Urich E, Wolter K, Prinz M, Becher B. Interleukin 18-independent engagement of interleukin 18 receptor-alpha is required for autoimmune inflammation. Nat Immunol. 2006;7(9):946-953.

48. LaRosa DF, et al. T cell expression of MyD88 is required for resistance to Toxoplasma gondii. Proc Natl Acad Sci U S A. 2008;105(10):3855-3860.

49. Lin L, et al. Th1-Th17 cells mediate protective adaptive immunity against Staphylococcus aureus and Candida albicans infection in mice. PLoS Pathog. 2009;5(12):e1000703.

50. Acosta-Rodriguez EV, et al. Surface phenotype and antigenic specificity of human interleukin 17-producing T helper memory cells. Nat Immunol. 2007;8(6):639-646.

51. Milner JD, et al. Impaired T(H)17 cell differentiation in subjects with autosomal dominant hyperIgE syndrome. Nature. 2008;452(7188):773-776.

52. Romani L, Kaufmann SH. Immunity to fungi: editorial overview [editorial]. Research in Immunology. 1998;149(4-5):277-281.

53. Fossiez F, et al. T cell interleukin-17 induces stromal cells to produce proinflammatory and hematopoietic cytokines. J Exp Med. 1996;183(6):2593-2603.

54. Jones CE, Chan K. Interleukin-17 stimulates the expression of interleukin-8, growth-related oncogene-alpha, and granulocyte-colony-stimulating factor by human airway epithelial cells. Am J Respir Cell Mol Biol. 2002;26(6):748-753.

55. Kawaguchi M, et al. Modulation of bronchial epithelial cells by IL-17. J Allergy Clin Immunol. 2001;108(5):804-809.

56. Laan M, et al. Neutrophil recruitment by human IL-17 via C-X-C chemokine release in the airways. JImmunol. 1999;162(4):2347-2352. 
57. Jaffar Z, Ferrini ME, Herritt LA, Roberts K. Cutting edge: lung mucosal Th17-mediated responses induce polymeric Ig receptor expression by the airway epithelium and elevate secretory IgA levels. J Immunol. 2009;182(8):4507-4511.

58. Lubberts E, et al. Requirement of IL-17 receptor signaling in radiation-resistant cells in the joint for full progression of destructive synovitis. J Immunol. 2005;175(5):3360-3368.

59. Leibundgut-Landmann S, Osorio F, Brown GD, Reis e Sousa C. Stimulation of dendritic cells via the dectin-1/Syk pathway allows priming of cytotoxic $\mathrm{T}$ cell responses. Blood. 2008;112(13):4971-4980.

60 . Adachi O, et al. Targeted disruption of the MyD88 gene results in loss of IL-1- and IL-18-mediated function. Immunity. 1998;9(1):143-150.

61. Rivera $\mathrm{A}$, et al. Innate immune activation and CD4(+) T cell priming during respiratory fungal infection. Immunity. 2006;25(4):665-675.

62. Fabien N, Bergerot I, Maguer-Satta V, Orgiazzi J, Thivolet $\mathrm{C}$. Pancreatic lymph nodes are early targets of $\mathrm{T}$ cells during adoptive transfer of diabetes in NOD mice. Journal of Autoimmunity. 1995;8(3):323-334.

63. Mattner F, et al. Genetically resistant mice lacking interleukin-12 are susceptible to infection with Leishmania major and mount a polarized Th2 cell response. Eur J Immunol. 1996;26(7):1553-1559.

64. Magram J, et al. IL-12-deficient mice are defective in IFN gamma production and type 1 cytokine responses. Immunity. 1996;4(5):471-481.

65. Wu C, Wang X, Gadina M, O’Shea JJ, Presky DH,
Magram J. IL-12 receptor beta 2 (IL-12R beta 2)deficient mice are defective in IL-12-mediated signaling despite the presence of high affinity IL-12 binding sites. IImmunol. 2000;165(11):6221-6228.

66 . Finotto S, et al. Development of spontaneous airway changes consistent with human asthma in mice lacking T-bet. Science. 2002;295(5553):336-338.

67. Glaccum $\mathrm{MB}$, et al. Phenotypic and functional characterization of mice that lack the type I receptor for IL-1. J Immunol. 1997;159(7):3364-3371.

68. Hoshino K, et al. Cutting edge: generation of IL-18 receptor-deficient mice: evidence for IL-1 receptorrelated protein as an essential IL-18 binding receptor. J Immunol. 1999;162(9):5041-5044.

69. Nakae S, et al. Antigen-specific T cell sensitization is impaired in IL-17-deficient mice, causing suppression of allergic cellular and humoral responses. Immunity. 2002;17(3):375-387.

70. Thieu VT, et al. Signal transducer and activator of transcription 4 is required for the transcription factor T-bet to promote Thelper 1 cell-fate determination. Immunity. 2008;29(5):679-690.

71. Harvey RP, Schmid ES, Carrington CC, Stevens DA. Mouse model of pulmonary blastomycosis: utility, simplicity, and quantitative parameters. Am Rev Respir Dis. 1978;117(4):695-703.

72. Brandhorst TT, Wüthrich M, Warner T, Klein B. Targeted gene disruption reveals an adhesin indispensable for pathogenicity of Blastomyces dermatitidis. J Exp Med. 1999;189(8):1207-1216.

73. Veldhoen M, Hirota K, Christensen J, O'Garra A,
Stockinger B. Natural agonists for aryl hydrocarbon receptor in culture medium are essential for optimal differentiation of Th17 T cells. J Exp Med. 2009;206(1):43-49.

74. Chen CJ, et al. MyD88-dependent IL-1 receptor signaling is essential for gouty inflammation stimulated by monosodium urate crystals. J Clin Invest. 2006;116(8):2262-2271.

75. Finkel-Jimenez B, Wüthrich M, Klein BS. BAD1, an essential virulence factor of Blastomyces dermatitidis, suppresses host TNF-alpha production through TGF-beta-dependent and -independent mechanisms. J Immunol. 2002;168(11):5746-5755.

76. Daley JM, Thomay AA, Connolly MD, Reichner JS, Albina JE. Use of Ly6G-specific monoclonal antibody to deplete neutrophils in mice. J Lenkoc Biol. 2008;83(1):64-70.

77. Fleming TJ, Fleming ML, Malek TR. Selective expression of Ly-6G on myeloid lineage cells in mouse bone marrow. RB6-8C5 mAb to granulocytedifferentiation antigen (Gr-1) detects members of the Ly-6 family. J Immunol. 1993;151(5):2399-2408.

78. Fisher LD, van Belle G. The Bonferroni method (B method). Biostatistics: A Methodology for the Health Sciences. New York, New York, USA:John Wiley and Sons; 1993:611-613.

79. Wüthrich M, Filutowicz HI, Allen HL, Deepe GS, Klein BS. V\{beta $\} 1+$ J beta $\} 1.1+/ V\{a l p h a\} 2+$ $\mathrm{J}\{$ alpha\}49+ CD4+ T Cells Mediate Resistance against Infection with Blastomyces dermatitidis. Infect Immun. 2007;75(1):193-200. 